\title{
Predatory functional response and fitness parameters of Orius strigicollis Poppius when fed Bemisia tabaci and Trialeurodes vaporariorum as determined by age-stage, two-sex life table
}

\author{
Shakeel UR Rehman ${ }^{1}$, Xingmiao Zhou Corresp., 1 , Shahzaib Ali ${ }^{1}$, Muhammad Asim Rasheed ${ }^{1}$, Yasir Islam ${ }^{1}$, Muhammad \\ Hafeez $^{2}$, Muhammad Aamir Sohail ${ }^{3}$, Haris Khurram ${ }^{4}$ \\ ${ }^{1}$ Hubei Insect Resources Utilization and Sustainable Pest Management Key Laboratory, College of Plant Science and Technology, Huazhong Agricultural \\ University, Wuhan, China \\ ${ }^{2}$ State Key Laboratory Breeding Base for Zhejiang Sustainable Pest and Disease Control, Institute of Plant Protection and Microbiology, Zhejiang Academy \\ of Agricultural Sciences, Hangzhou, China \\ 3 The Key Lab of Plant Pathology of Hubei Province, Huazhong Agricultural University, Wuhan, Hubei, China \\ 4 Department of Sciences and Humanities, National University of Computer and Emerging Sciences, Chiniot-Faisalabad Campus, Chiniot, Pakistan \\ Corresponding Author: Xingmiao Zhou \\ Email address: xmzhou@mail.hzau.edu.cn
}

Background: The polyphagous predatory bug $O$. strigicollis is an active predator used to control thrips and aphids. The whitefly species Bemisia tabaci and Trialeurodes vaporariorum are voracious pests of different economic agricultural crops and vegetables. Method: In this study, Holling disc equation and age-stage, two-sex life table technique was used to investigate the functional response and biological traits of third instar nymphs and adult female $O$. strigicollis when presented third instar nymphs of both whitefly species as prey. Results: The results showed a type II functional response for each life stage of $O$. strigicollis when fed each whitefly species. The calculated prey handling time for different $O$. strigicollis life stages were shorter when fed $T$. vaporariorum than when fed $B$. tabaci nymphs. In contrast, the nymphal development of $O$. strigicollis was significantly shorter when fed $B$. tabaci than $T$. vaporariorum nymphs. Additionally, the total preoviposition period of adult females was statistically shorter when fed $B$. tabaci nymphs than $T$. vaporariorum nymphs. Furthermore, the survival rates and total fecundity of $O$. strigicollis were higher when fed $B$. tabaci than $T$. vaporariorum. There were no significant differences in any population parameters of $O$. strigicollis when fed either whitefly species. These results show that $O$. strigicollis could survive and maintain its populations on both species of whitefly and could therefore serve as a biological control agent in integrated pest management (IPM). 
1 Predatory functional response and fitness parameters of Orius strigicollis Poppius

2 when fed Bemisia tabaci and Trialeurodes vaporariorum as determined by age-

3 stage, two-sex life table

4 Running Title: development and survival of $O$. strigicollis fed on two whitefly species

5 Shakeel Ur Rehman ${ }^{1}$, Xingmiao Zhou ${ }^{1}$, Shahzaib Ali ${ }^{1}$, Muhammad Asim Rasheed ${ }^{1}$, Yasir Islam ${ }^{1}$,

6 Muhammad Hafeez ${ }^{2}$, Muhammad Aamir Sohail ${ }^{3}$ and Haris Khurram ${ }^{4}$

7 1. Hubei Insect Resources Utilization and Sustainable Pest Management Key Laboratory, 8 College of Plant Science and Technology, Huazhong Agricultural University, Wuhan $9 \quad 430070$, P. R. China.

2. State Key Laboratory Breeding Base for Zhejiang Sustainable Pest and Disease Control, Institute of Plant Protection and Microbiology, Zhejiang Academy of Agricultural Sciences, Hangzhou, Zhejiang, China.

3. The Key Lab of Plant Pathology of Hubei Province, Huazhong Agricultural University, Wuhan 430070, Hubei, China.

4. Department of Sciences and Humanities, National University of Computer and Emerging Sciences, Chiniot-Faisalabad Campus, Pakistan.

*Corresponding Author: Xingmiao Zhou; Email: xmzhou@mail.hzau.edu.cn

First author: Shakeel Ur Rehman; Email: Shakeel.entomologist@hotmail.com Co-authors Email address:

shahzaibali@webmail.hzau.edu.cn, asim_ento@outlook.com, yasir_islam@outlook.com, hafeez_203@yahoo.com, amirsohai1306@gmail.com and haris.khurram@nu.edu.pk 
22 Abstract

23 Background: The polyphagous predatory bug $O$. strigicollis is an active predator used to control thrips and aphids. The whitefly species Bemisia tabaci and Trialeurodes vaporariorum are voracious pests of different economic agricultural crops and vegetables.

Method: In this study, Holling disc equation and age-stage, two-sex life table technique was used to investigate the functional response and biological traits of third instar nymphs and adult female O. strigicollis when presented third instar nymphs of both whitefly species as prey.

Results: The results showed a type II functional response for each life stage of $O$. strigicollis when fed each whitefly species. The calculated prey handling time for different $O$. strigicollis life stages were shorter when fed T. vaporariorum than when fed B. tabaci nymphs. In contrast, the nymphal development of $O$. strigicollis was significantly shorter when fed B. tabaci than $T$. vaporariorum nymphs. Additionally, the total pre-oviposition period of adult females was statistically shorter when fed B. tabaci nymphs than T. vaporariorum nymphs. Furthermore, the survival rates and total fecundity of $O$. strigicollis were higher when fed $B$. tabaci than $T$. vaporariorum. There were no significant differences in any population parameters of $O$. strigicollis when fed either whitefly species. These results show that $O$. strigicollis could survive and maintain its populations on both species of whitefly and could therefore serve as a biological control agent in integrated pest management (IPM).

Key words: Orius strigicollis (Anthocoridae), functional response, biological traits, predation, whitefly species, biological control. 


\section{Introduction}

Invasive insect pests can significantly disturb native insect communities and cause considerable damage to agriculture and forests (Pimentel et al. 2000). Among these pests, whiteflies (Hemiptera: Aleyrodidae) are the most damaging insect pests to agricultural crops globally, including China where more than 1450 species are known (Martin et al. 2000; Anderson et al. 2004; Lapidot et al. 2014). Included in these species are the silver-leaf whitefly (Bemisia tabaci) and greenhouse whitefly (Trialeurodes vaporariorum), which are generally considered responsible for major economic losses. However, B. tabaci is thought to be a complex of morphologically indistinguishable sibling species, referred to as different biotypes (Wraight et al. 2017). They considered to be one of the most significant plant pests and colonizes over 600 host plants, causing significant damage (Polston et al. 2014). This specie of whitefly is distributed globally (De Barro 1995; De Barro et al. 2000; De Barro et al. 2005) and causes significant damage to crop yield and quality by feeding on plant phloem and secreting honeydew that stimulates the rapid growth of molds (Colvin et al. 2006; Prijović et al. 2013). However, the most significant problem associated with outbreaks of B. tabaci is the transmission of plant viruses (Navas-Castillo et al. 2011). Bemisia tabaci has been reported as the vector for the transmission of over 300 viral species in major economically important agricultural and vegetables crops (Gilbertson et al. 2015). Similarly, Trialeurodes vaporariorum, commonly known as greenhouse whitefly, is also considered an important pest of vegetable and agricultural crops but transmits fewer viruses than does $B$. tabaci (Wisler et al. 1998; Jones 2003; Brown 2007; Navas-Castillo et al. 2011; López et al. 2012). However, because of its short life cycle, this species has been considered a more prevalent insect pest in greenhouse (Simmonds et al. 2002). Trialeurodes vaporariorum can also adapt to cold climates better than B. tabaci does and is common at high elevations (Barboza et al. 2019). Because 
66 of its resistance to insecticides such as neonicotinoids, T. vaporariorum has received much

67 research attention (Gorman et al. 2007; Karatolos et al. 2011; Pym et al. 2019).

68

Extensive use of pesticides not only causes environmental contamination and ozone layer depletion, but also creates serious health problems in mammals and creates toxic conditions for beneficial insect species (Shaaya et al. 1997; Yoza et al. 2005). Hence, to reduce insecticide use, biological control methods such as use of natural predators, resistant varieties, and plants extracts are important in controlling pests in modern integrated pest management (IPM) programs (Kageyama et al. 2010; Yazdani \& Zarabi 2011; Yang et al. 2012; Asare-Bediako et al. 2014).

The genus Orius (Heteroptera: Anthocoridae) is the largest group of flower bugs, containing around eighty species globally. They are polyphagous predators of small and softbodied insects considered pests in agriculture and forestry, including spider mites, aphids, thrips, and whiteflies in protected and open-field crops within its native range of Asia (Herring 1966; Hernández 1999; Postle et al. 2001; Carpintero 2002; Arnó et al. 2008; Yamada et al. 2016; Zhao et al. 2017). The artificial introduction of $O$. sauteri as a biological control agent provides potential control against small insect pests on pepper and eggplant, especially under greenhouse conditions (Jiang et al. 2011; Yin et al. 2013). Orius laevigatus is an effective biological control species in Europe and is widely used in augmentative release programs (Van Lenteren \& Bueno 2003). Studies have been conducted into predation by O. albidipennis, $O$. insidiosus, O. majusculus, and O. niger on different prey species (Fritsche \& Tamo 2000; Tommasini et al. 2004; Rutledge \& O’Neil 2005). Similarly, O. majusculus and O. laevigatus were reported as potential natural enemies of B. tabaci eggs, nymphs, and adults (Arnó et al. 2008).

The predatory flower bug Orius strigicollis Poppius (Heteroptera: Anthocoridae) which was previously known as Orius similis Zheng (Heteroptera: Anthocoridae) (junior synonym of $O$. 
89

90

91

92

93

94

95

96

97

98

strigicollis) (Yasunaga, 1997; Jung et al., 2013), also called "minute predatory flower bug", is a common and effective natural enemy present in cultivated fields in China and is used as a biological control agent against many small pests of economically important agricultural crops (Zhang et al. 2012). Both pre-adult and adult stages prey on lepidopteran insects including eggs or newly hatched larvae of Pectinophora gossypiella, Anomis flava, and Helicoverpa armigera as well as Frankliniella formosae, Aphis gossypii, and Tetranychus cinnabarinus. Large populations of O. strigicollis in cotton fields are useful as biological control agents (Zhou \& Lei 2002). This Anthocorid species has many features that make it a good biological control agent, such as high searching efficiency, the ability to increase population levels with outbreaks coinciding with prey density, and an aptitude to aggregate in regions of high prey populations (Hodgson \& Aveling 1988). Mass rearing of $O$. strigicollis and the subsequent augmentative release into crop fields leads to the control of many insect pests, decreasing their populations and hence reducing the use of pesticides (Tommasini et al. 2004; Bonte \& De Clercq 2011). However, it is important to estimate the effectiveness of a predator before using it in an integrated pest program (Fathipour et al. 2006).

The potential of a predator to control a pest depends upon its functional response to different populations of prey (Butt \& Xaaceph 2015). Therefore, the efficiency of a predator can be assessed by its functional response (i.e., changes in attack rate in response to variations of prey populations $\mathrm{x}$ number of prey consumed per unit time in relation to prey density (Riechert \& Harp 1987). Four types of functional response have been defined based on the predation rate of a predator as a function of prey density: type I (a linear increase), type II (an increase with a slowdown at high prey densities), type III (a sigmoidal increase) and type IV (a dome shape in prey consumption increase (Holling 1961; Pervez 2005; Sakaki \& Sahragard 2011). Similarly, the 
112 biological traits of a predator, influenced by changes in prey species, greatly affect its predation

113 activity. Thus, this study aims to investigate the interaction of the predator $O$. strigicollis with the

114 prey species B. tabaci and T. vaporariorum under controlled conditions. The main aim is to

115 evaluate the functional response parameters, fitness parameters, biological traits, and population

116 parameters of $O$. strigicollis when fed B. tabaci and $T$. vaporariorum nymphs separately.

\section{Material and Methods}

\section{Insect rearing}

Adults of $O$. strigicollis were captured from vegetable and cotton fields of the Huazhong

Agricultural University (Wuhan, China) and mass reared in an insectarium following the method transparent boxes $(23.5 \times 22.0 \times 5.5 \mathrm{~cm})$ with ventilation in the lid. Nymphs and adults of $O$.

strigicollis were supplied black aphids (Aphis fabae). Small stems of Vitex negundo (3-4) wrapped

with wet cotton over the end were provided as oviposition substrate. The environmental conditions of $28 \pm 1{ }^{\circ} \mathrm{C}$ temperature, $70 \pm 5 \%$ R.H and a photoperiod of $16 \mathrm{~L}: 8 \mathrm{D}$ h at a light intensity of 1400-1725 lux.

Adult B. tabaci were collected from vegetables grown in greenhouses and from other crops from open fields located in the campus of the Huazhong Agricultural University. They were then moved to insectaria and released on potted cotton (Gossypium hirsutum) plants $(10 \mathrm{~cm})$ to develop the stock culture for the experiments (Khan \& Wan 2015; Tomar et al. 2017). The stock culture of

132 (Chongqing, China). Large screen cages $(65 \times 65 \times 65 \mathrm{~cm})$ were used as arenas for both whitefly 133 species. The obtained T. vaporariorum individuals were released on tobacco (Nicotiana tabacum) 
134 plants $(10 \mathrm{~cm})$ for mass rearing (Haiyan et al. 2017; Wei et al. 2018). The following environmental

135 conditions were maintained inside the insectaria: temperature $26 \pm 1^{\circ} \mathrm{C}, \mathrm{RH} 65 \pm 5 \%$, and a

136 photoperiod of 16 L: $8 \mathrm{D}$ h at a light intensity of 1400-1725 lux.

137 Functional Response of $\boldsymbol{O}$. strigicollis

138 The third instar nymphs and three-day old adult females of $O$. strigicollis were collected

139 from the insectaria and fed third instar nymphs of B. tabaci and T. vaporariorum for $48 \mathrm{~h}$ separately

140 and starved for $24 \mathrm{~h}$. The predatory bugs were then individually transferred to small petri dishes

141 (9 $\mathrm{cm}$ in diameter and $2 \mathrm{~cm}$ in depth) and supplied separately with third instar nymphs of $B$. tabaci

142 and $T$. vaporariorum with different densities (4, 6, 8, 10, 12, and 14) per predator. After $24 \mathrm{~h}$,

143 predators were removed, and the prey consumed by both life stages of $O$. strigicollis counted under

144 stereomicroscope (Liu Pingping, et al., 2018). Bugs were used once only. All the dead/empty

145 nymphs of both whitefly species were assumed killed by the predator as preliminary study

146 indicated $100 \%$ survival of bugs in the absence of whitefly nymphs. Thirty replications of the

147 experiments involving the third instar nymphs and adult females of $O$. strigicollis were made for

148 each treatment/density with both prey species separately.

149 Life table study

150 Nymphal development

151 Approximately sixty freshly laid healthy eggs of $O$. strigicollis were isolated from the

152 insectaria and incubated until hatched. All collected eggs of $O$. strigicollis were equally distributed

153 to feed on B. tabaci and T. vaporariorum third instar nymphs separately. After hatching, $O$.

154 strigicollis neonates $(\leqslant 24 \mathrm{~h})$ were isolated in small Petri dishes (diameter: $9 \mathrm{~cm}$; depth: $2 \mathrm{~cm})$

155 firmed with filter paper. From the results of functional responses, we supplied fifteen third instar 
156 nymphs of $B$. tabaci and $T$. vaporariorum separately to each individual of the predatory bug as

157 food. Dead/empty nymphs of whitefly were replaced every day. A stem of $V$. negundo was placed

158 in each Petri dish to provide shelter and moisture to the predatory bugs. The end of each stem was

159 wrapped with wet cotton to keep them moist. Thirty nymphs were used in the experiment with

160 three biological replicates for each prey species. Developmental time for each nymphal instar was

161 measured. Individuals that died before reaching the adult stage were also recorded. Sex was

162 confirmed as soon as the adults emerged.

163

164

165

166

167

168

169

170

171

172

173

174

175

176

\section{Adult longevity and fecundity}

Newly emerged male and female $O$. strigicollis adults were paired for mating. Females that mated for more than 1.5 min were considered to have been mated (Butler and O'Neil, 2006). Each mated female was placed separately in a new cylindrical translucent vial $(2.5 \times 14 \mathrm{~cm}$ diameter and length respectively) enclosed with an adequate mesh nylon screen. A small section of Vitex negundo stem was offered to each $O$. strigicollis female as an oviposition substrate. Each stem was wrapped with moist cotton at the end to provide moisture to the stem as well as the bugs using the method of Zhou et al. (2006). Bemisia tabaci and T. vaporariorum nymphs $(\mathrm{n}=15)$ were supplied into each vial as a source of food for female O. strigicollis. Stems of Vitex negundo were examined under a stereomicroscope $(15 \times)$ to confirm egg laying. The stem was changed every day after the female laid the first egg. The total number of eggs laid by each female was counted under a stereomicroscope $(15 \times)$. All predatory bugs were observed until they died. Development period, survival rate, pre-oviposition and oviposition period, fecundity, and longevity of female and male adults of $O$. strigicollis were recorded. 
177

178

179

180

181

182

183

184

185

186

187

188

189

190

191

192

193

194

195

196

\section{Data analysis}

\section{Functional response}

The shape of the curve was find using the polynomial logistic regression following the method describe by Pervez, 2005; Butt and Xaaceph, 2015 and Varshney et al. 2018. The polynomial function described the relationship between the proportion of prey consumed $\left(\mathrm{N}_{\mathrm{a}}\right)$ in relation to the density of prey offered $\left(\mathrm{N}_{0}\right)$ (Holling, 1959a; Holling, 1959b). Hence, a cubic model was applied in a logistic regression analysis (Juliano, 2001).

$$
\frac{\mathrm{N}_{\mathrm{a}}}{\mathrm{N}_{0}}=\frac{\exp \left(\mathrm{P}_{\mathrm{o}}+\mathrm{P}_{1} \mathrm{~N}_{\mathrm{o}}+\mathrm{P}_{2} \mathrm{~N}_{\mathrm{o}}^{2}+\mathrm{P}_{3} \mathrm{~N}_{\mathrm{o}}^{3}\right)}{1+\exp \left(\mathrm{P}_{\mathrm{o}}+\mathrm{P}_{1} \mathrm{~N}_{\mathrm{o}}+\mathrm{P}_{2} \mathrm{~N}_{\mathrm{o}}^{2}+\mathrm{P}_{3} \mathrm{~N}_{\mathrm{o}}^{3}\right)}
$$

In this equation, $\mathrm{P}_{0}, \mathrm{P}_{1}, \mathrm{P}_{2}$, and $\mathrm{P}_{3}$ represent the intercept, linear, quadric, and cubic coefficients, respectively. The negative and positive values of linear coefficient $\left(\mathrm{P}_{1}\right)$ define type II and III functional responses, respectively. The cubic expression will often provide a good fit to a type II and III responses and will provide a good starting point for fitting a logistic regression (Trexler et al. 1988; Trexler and Travis 1993; Juliano, 2001). Modifying the Holling disc equation through reciprocal linear transformation, handling time $\left(\mathrm{T}_{\mathrm{h}}\right)$ and the attack rate $(a)$ were calculated (Livdahl \& Stiven 1983). This method is famous because of its simplicity and accuracy (Veeravel and Baskaran 1997; Pervez and Omkar 2003; Omkar and Pervez 2004). The modified Holling equation, after reciprocal linear transformation is as follows:

$$
1 / \mathrm{N}_{\mathrm{a}}=1 / \alpha \mathrm{TN}_{0}+\mathrm{T}_{\mathrm{h}} / \mathrm{T}+\varepsilon
$$

Where $\mathrm{N}_{\mathrm{a}}$ is the number of prey killed by predators during time (T: $24 \mathrm{~h}$ ). $\mathrm{N}_{0}$ is the density of prey, $\alpha$ is the attack rate and $T_{h}$ is the predator handling time for one prey item. Hence, the 
197 variables used in the regression were $\mathrm{y}=\mathrm{ax}+\mathrm{b}+\varepsilon$. The inverse mathematical function for curve

198 estimation was used to estimate the values of $\alpha$ and $T_{h}$ (Ali et al., 2011). For each prey density we 199 calculated total handling time $\left(\mathrm{Th}_{\text {total }}=\mathrm{T}_{\mathrm{h}} \times \mathrm{N}_{\mathrm{a}}\right)$, search time $\left(\mathrm{Ts}=\mathrm{T}-\mathrm{T}_{\mathrm{h} \text { total }}\right)$, attack rate $\left(\alpha=\mathrm{N}_{\mathrm{a}} /\right.$

$200\left(\mathrm{~N}_{0} \times \mathrm{Ts}\right)$ ), and search efficiency $\left(\mathrm{E}=\mathrm{N}_{\mathrm{a}} / \mathrm{N}_{0}\right)$ (Hassell 2000; Rocha \& Redaelli 2004). All statistical

201 analyses were performed in MINITAB 19.

\section{Life table analysis}

The data obtained from experiments were analyzes based on the age-stage, two-sex life table theory using Twosex-MSChart, a computer program (Chi, 1988; Chi and Liu, 1985; Huang and Chi 2011; Qi Chen et al 2017; Farooq et al. 2018). The different biological traits and demographic parameters such as eggs, nymphs and adult development, oviposition, preChi (2015).

In the age-stage, two-sex life table, the age-specific survival rate $\left(l_{x}\right)$ and fecundity $\left(m_{x}\right)$ were calculated using the equation (1) and (2) respectively.

$$
l_{x}=\sum_{j=1}^{k} \mathrm{~s}_{x j}
$$

$$
m_{x}=\frac{\sum_{j=1}^{k} s_{x j} f_{x j}}{\sum_{j=1}^{k} s_{x j}}
$$

213 In this equation, $S_{x j}$ is the age-stage specific survival rate of $O$. strigicollis $(x=$ age which is in days 214 and $j=$ stage) which describe the probability of survival of neonate to age $x$ and stage $j$, meanwhile, $215 f_{x j}$ describe age-stage specific fecundity of adult female (Chi and Liu, 1985). The Euler-Lotka 216 equation was used to estimate the intrinsic rate of increase $(r)$ following the method of iterative 217 division with the age index from 0 using equation (3) (Goodman, 1982). 


$$
\sum_{x=0}^{\infty} \mathrm{e}^{-r(x+1)} l_{x} m_{x}=1
$$

219 The values of $\left(R_{0}\right)$ which described the ability of the female to produce a mean number of offspring

220 in his lifetime, was calculated as

$$
\sum_{x=0}^{\infty} l_{x} m_{x}=R_{0}
$$

222 The relation between female and $R_{0}$ can describe as

$$
R_{0}=F \frac{N_{f}}{N}
$$

224 Here $N$ and $N_{f}$ represent the total number of $O$. strigicollis used in the experiment and the number 225 of female adults respectively (Chi, 1988). The gross reproduction rate $G R R$ and rate of increase $226(\lambda)$ were estimated as

$$
G R R=\sum_{x=0}^{\infty} m_{x}
$$

$$
\lambda=e r
$$

229 The mean generation time $(T)$ that a population required to rise to $R_{0}$-fold of its size i.e. $e^{r T}=R_{0}$ 230 or $\lambda^{T}=R_{0}$ at the stable age-stage distribution was intended using the equation

$$
T=\frac{\ln R_{0}}{r}
$$
developmental time of each stage, fecundity, adult longevity and population parameters (Akca et al., 2015; Akköprü et al., 2015; Tuan et al., 2015). To compare the values, a pair bootstrap test based on the confidence of the interval of difference was used (Chi, 2015; Pru et al., 2015). To 
236 obtain the curves of survival rate, fecundity, life expectancy and reproductive vales, Sigma Plot

23712.0 was used.

\section{Results}

\section{Functional response of $\boldsymbol{O}$. strigicollis}

The results of the logistic regression analysis for third instar nymphs of $O$. strigicollis were

highly significant $(P<0.05)$ suggesting a type II functional response as the linear coefficient $(\mathrm{P} 1)$ was negative against nymphs of both $B$. tabaci and T. vaporariorum (Table 1). Similarly, the adult females also showed a type II functional response against both prey species, although the parameters were not significant.

The functional response curves of different life stages of $O$. strigicollis to third instar nymphs of B. tabaci and T. vaporariorum at different densities are show in Fig. 1. The number of nymphs of both prey species consumed by third instar nymphs and adult females of $O$. strigicollis increased with increases in the prey density from 4 to 8 nymphs per predator, but plateaued with no significant increase in prey consumption with densities of more than 8 nymphs per predator. When only four nymphs of $B$. tabaci and T. vaporariorum were provided, the third instar nymphs of $O$. strigicollis consumed a mean of $3.8 \pm 0.097$ and $3.3 \pm 0.128$ nymphs per predator per day, respectively, indicating that the predator is more efficient at finding whitefly nymphs at low prey densities. When provided with third instar nymphs of $B$. tabaci and T. vaporariorum, the maximum and minimum prey consumption levels of third instar nymphs of $O$. strigicollis were $(95 \%$ and $46.4 \%)$ and $(82.5 \%$ and $44 \%)$, respectively. However, there were no significant differences found 
257 nymphs of B. tabaci and T. vaporariorum, respectively. The minimum percentage of B. tabaci and

$258 T$. vaporariorum nymphs killed by adult female $O$. strigicollis was $48 \%$ and $51 \%$, respectively. 


\section{Functional response parameters}

260

The parameters of functional response (handling time $\left(\mathrm{T}_{\mathrm{h}}\right)$, attack rate $(\mathrm{a})$, and maximum

261

predation rate) of different stages of $O$. strigicollis against whitefly species are listed in Table 2.

262

There were no differences estimated in the $\mathrm{T}_{\mathrm{h}}$ of third instar nymphs of $O$. strigicollis against both whitefly species. However, adult females undertook shorter handling times $(1.75 \mathrm{~h})$ when pursuing, subduing, and consuming $T$. vaporariorum third instar nymphs when compared with the handling times for $B$. tabaci $(2.45 \mathrm{~h})$. In contrast, the coefficient of attack rate was higher, ranging from 0.05 to 0.06 , when third instar nymphs and adult females of $O$. strigicollis were fed nymphs of B. tabaci compared to T. vaporariorum (Table 3). However, there were no significant difference noted for different life stages of $O$. strigicollis in attack rate. The maximum predation rate $\left(\mathrm{T} / \mathrm{T}_{\mathrm{h}}\right)$ of third instar nymphs of $O$. strigicollis per individual was higher $\left(9.82 \mathrm{~d}^{-1}\right)$ for $T$. vaporariorum nymphs compared to $B$. tabaci $\left(9.78 \mathrm{~d}^{-1}\right)$. Similarly, the maximum predation rate of adult females was $\left(13.70 \mathrm{~d}^{-1}\right)$ and $\left(11.12 \mathrm{~d}^{-1}\right)$ for $T$. vaporariorum and $B$. tabaci nymphs, respectively. The whitefly species are given in Table 3 . The $\mathrm{T}_{\mathrm{h}}$ for third instar nymphs and adult females of $O$. efficiency show an inverse relationship with both prey densities. The attack rates of both life stages of $O$. strigicollis were similar with no significant differences at different densities of both prey species.

\section{Growth, development, and longevity of $O$. strigicollis}

279 Developmental characteristics of $O$. strigicollis when fed of whitefly species (B. tabaci and $T$. vaporariorum) are listed in Table 4. The development time for nymphal instar of N1-N4 of $O$. strigicollis took statistically longer when fed T. vaporariorum than when fed B. tabaci. 
282 However, there were no significant differences in development of fifth instar $O$. strigicollis

283 nymphs against both whitefly species. In addition, higher mortality rates were observed in the fifth

284 instar when fed T. vaporariorum nymphs than when fed B. tabaci. The results also showed that

285 longevity of both male and female $O$. strigicollis was statistically similar when $B$. tabaci and $T$.

286 vaporariorum were provided as prey (Table 4). It was also observed that more individuals of the

287 predatory bug survived and successfully reached the adult stage when fed $B$. tabaci nymphs

288 (86.66\%) than when fed T. vaporariorum nymphs (56.70\%).

289 Fecundity and oviposition of female adults

290 No significant effects of the presence of the two whitefly species were observed on adult pre291 ovipositional period (APOP) of $O$. strigicollis (2.35 days for B. tabaci and 2.4 days for $T$.

292 vaporariorum; Table 5). However, the total pre-ovipositional period (TPOP) of O. strigicollis was 293 significantly longer when offered T. vaporariorum nymphs (20.5 days) compared to B. tabaci 294 (19.82 days, Table 5).

It was also observed that the total reproductive days of female adult $O$. strigicollis were statistically similar with no significant difference for both whitefly species (8.29 and 7.80 days when fed B. tabaci and T. vaporariorum, respectively, Table 5). Furthermore, no significant difference was recorded in total female fecundity against both prey species; however, more eggs were laid by adult females when fed B. tabaci nymphs (54.18 eggs) than T. vaporariorum (49.82 eggs). More females were produced when fed B. tabaci than T. vaporariorum.

\section{Population parameters of $\boldsymbol{O}$. strigicollis}

The influence of the two prey species on the population parameters of $O$. strigicollis are listed in

Table 6. No significant differences were found in $O$. strigicollis population parameters when fed 
304 B. tabaci and T. vaporariorum separately. The intrinsic rate of increase $(r)$ and finite rate of

305 increase $(\lambda)$ for $O$. strigicollis were $\left(0.13 \mathrm{~d}^{-1}\right.$ and $1.14 \mathrm{~d}^{-1}$, respectively) when fed nymphs of $B$.

306 tabaci and $\left(0.11 \mathrm{~d}^{-1}\right.$ and $\left.1.12 \mathrm{~d}^{-1}\right)$ when fed $T$. vaporariorum. However, the highest net

307 reproductive rate $\left(R_{0}\right)$ occurred when $O$. strigicollis was fed $B$. tabaci (30.70 offspring per female)

308 than when fed T. vaporariorum (18.27). Furthermore, the mean generation time of individuals $(T)$

309 and the values of GRR were higher when $B$. tabaci was offered as prey (25.46 d and 54.62)

310 compared to T. vaporariorum (26.61 d and 61.57; Table 6).

\section{Age-stage and age-specific survival of $O$. strigicollis}

312 The Fig. 2 explains the age-stage specific survival rate $\left(S_{x j}\right.$; the possibility a newly hatched

313 individual that will successfully survive to age $x$ and stage $j$ ) of $O$. strigicollis when fed $B$. tabaci

314 and T. vaporariorum. Overlap occurs between stages as a result of variations in the developmental

315 rate of individuals. When fed nymphs of $B$. tabaci, $86.66 \%$ of $O$. strigicollis eggs successfully

316 survived and reached to the adult stage. However, the survival rate was significantly lower (56.7\%)

317 when $O$. strigicollis were fed T. vaporariorum nymphs.

Age-specific survival rate $\left(l_{x}\right.$; a simplified form of $\left.S_{x j}\right)$, age-stage specific fecundity $\left(f_{x}\right)$, age-specific total fecundity of the whole population $\left(m_{x}\right)$, and age-specific maternity $\left(l_{x} m_{x}\right.$; formed on the basis of $f_{x}$ and $m_{x}$ ) of $O$. strigicollis when fed B. tabaci and T. vaporariorum are presented in Fig. 3. As age increased, the $l_{x}$ of $O$. strigicollis decreased and showed an inverse relationship for both prey species. The peak of the $m_{x}$ curve was at 26.98 days (5.14 eggs) and 31.09 days (5.72 eggs) when $O$. strigicollis fed on $B$. tabaci and $T$. vaporariorum, respectively. The peak of $f_{x}$ was

324 at 24.90 days (8.45 eggs) and 30.88 days (7.80 eggs) for B. tabaci and T. vaporariorum nymphs 325 respectively. 


\section{Life expectancy and reproductive values}

The curves for life expectancy $\left(e_{x j}\right)$ of $O$. strigicollis at each stage when presented with $B$.

328

329

330

331

332

333

334

335

336

337

338

339

340

341

342

tabaci and T. vaporariorum are shown in Fig. 4. It describes the estimated survival of an individual of age $x$ and stage $j$ at a later age $x$. The life expectancy of a newly hatched egg of $O$. strigicollis was 28.57 and $24.91 \mathrm{~d}$ on $B$. tabaci and $T$. vaporariorum respectively. The age-stage reproductive values $\left(v_{x j}\right)$ of adult female $O$. strigicollis when exposed to different species of whitefly are shown in Fig. 5. Age-stage specific reproductive value is a measure of the contribution of an individual (from age $x$ and stage $j$ ) to a future population. When adult female $O$. strigicollis fed on $B$. tabaci, the highest peak was observed at 21 days, which was greater than when offered $T$. vaporariorum (19.79 days). The Age-stage specific reproductive curve $\left(V_{x j}\right)$ indicated that the presence of $B$. tabaci had a more positive effect on $O$. strigicollis reproduction than T. vaporariorum.

\section{Discussion}

To quantify the ability of a predator to combat agricultural pests, the Holling functional response model has been used for several years (Ganjisaffar \& Perring 2015; Yazdani \& Keller 2016). Handling time $\left(T_{h}\right)$ and attack rate $(a)$ are considered key parameters in explaining oscillations in predator and prey interactions (Wang et al. 2019). A predator's functional response to its prey plays a significant role in the effect it has on a prey population (Begon et al. 1986). Similarly, life table studies enable us to understand the ecology of an organism and supply some crucial tools to study vital biological functions such as growth, survival, and reproductive rate when an organism is in a diverse environment. Some drawbacks have been found in Jackknife methods; therefore, a bootstrap method using 100,000 resamples was developed to calculate population parameters with more accurate results (Huang \& Chi 2012; Huang \& Chi 2013). 
348 Numerous studies have investigated Orius spp. as a predator of B. tabaci, (Arnó et al. 2008; Adly

349 2016; Banihashemi et al. 2017; Zandi-Sohani et al. 2018; Shahpouri et al. 2019).

Our results indicate that the third instar nymphs and adult female of $O$. strigicollis show type II functional responses when fed separately on six different densities of B. tabaci and $T$.

352 vaporariorum third instar nymphs. With increases in prey density, the net prey consumption of both life stages of $O$. strigicollis increased until a plateau was reached. Predators with type II and III functional responses have a probability of being a stabilizing force in biological control programs (Fernández-arhex \& Corley 2003). Orius spp. have shown a type II functional response in numerous other studies (Holling 1965). A type II functional response was reported for $O$. albidipennis when it was fed T. tabaci (Madadi et al. 2007), Megalurothrips sjostedti (Thysanoptera: Thripidae) larvae (Gitonga et al. 2002), and Tetranychus turkestani (Acari: Tetranychidae) (Hasanzadeh et al. 2015). In contrast to our results, the adult female O. albidipennis showed a type III functional response when fed $B$. tabaci third instar nymphs (Shahpouri et al. 2019). Similarly, M. caliginosus showed a type III functional response when presented with nymphs of T. vaporariorum (Enkegaard et al. 2001). These contradictory results may be related to changes in predator species and differences in body size. Supporting our results, O. majusculus and $O$. laevigatus exhibited a type II functional response when fed nymphs of $T$. vaporariorum (Montserrat et al. 2000). Predator functional response is influenced by several factors, such size and density of predators and preys (Aljetlawi et al. 2004), temperature (Gitonga et al. 2002; Zamani et al. 2006), occurrence of alternative prey (Abrams 1990), and internal state of the predator (Hassell et al. 1976). In our study, the arena consisted of small Petri dishes. This small experimental arena accelerated the searching efficiency of the predatory bugs and enabled them to repeatedly attack prey that initially escaped (Wiedenmann \& O'Neil 1991). The optimal foraging 
371 theory of predator-prey relationships has helped reveal the influence of different prey densities on

372 predator handling time, searching time, and predation rate (Cook \& Cockrell 1978; Stephens \&

373 Krebs 1986). In our study, searching time decreased with increases in prey density for both third

374 instar nymphs and adult female of $O$. strigicollis.

To estimate the effectiveness of a predator in relation to its prey, handling time is thought to be a key parameter because it shows how long a predator takes to capture, subdue, kill, and digest a single prey item (Atlihan et al. 2010). In our study, the handling time was shortest when adult female $O$. strigicollis were offered $T$. vaporariorum nymphs. In contrast to our study, the (Shahpouri et al. 2019). However, long handling time enables increased nutrient consumption from prey and hence increases the persistence of predators (Montserrat et al. 2000). Recent studies have shown that handling time is higher when $O$. albidipennis preys on B. tabaci nymphs than eggs (Shahpouri et al. 2019). Similarly, handling time of O. laevigatus was longer than that for other Orius species when tested again different densities of thrips (Montserrat et al. 2000). Maximum prey consumption enhances the possibility of gaining optimal ratios between predators and pests. Hence it can be useful to accelerate the application of inoculative releases (Wang et al. 2019). Our results show that maximum predation occurred when adult female $O$. strigicollis fed on $T$. vaporariorum. Meanwhile, more nymphs were eaten by third instar nymphs of $O$. strigicollis when fed on T. vaporariorum. Higher prey densities (and thus greater prey availability) or decreases in searching area accelerate predator attack rates while reducing handling time (Hassell et al. 1976). In a previous study (Opit et al. 1997), lower prey densities induced reduction in predator searching activity to reduce the use of energy. In our study, no significant differences in attack rate were 
394

395

396

397

398

399

400

401

402

403

404

405

406

407

408

409

410

411

412

413

414

415

416

vaporariorum separately, even with six different densities. The attack rate did not therefore depend on prey densities (Holling 1959). However, our results showed higher attack rates with $B$. tabaci than $T$. vaporariorum for both third instar nymphs and adult females of $O$. strigicollis. In contrast to our results, previous work resulted in different values for handling time and attack rate when $O$. majuscules and O. laevigatus were fed T. vaporariorum (Montserrat et al. 2000). This may be due to changes in experimental design, environment, or predator species (Van Alphen \& Jervis 1996). The polyphagous predatory species of Orius prey on a broad range of arthropods. Additionally, prey type can significantly alter the activity of their predators (Bonte et al. 2015). The developmental and reproductive performance and fitness of predators in relation to particular prey types highlights their potential as active biological control agents (Grenier \& De Clercq 2003).

The results obtained from the age-stage two-sex life table analysis indicate that $O$. strigicollis can survive and build strong populations when feeding on different species of whiteflies (B. tabaci and T. vaporariorum). However, we found that the nymphal developmental durations of the predator were significantly longer when praying on nymphs of $T$. vaporariorum than on nymphs of B. tabaci. Moreover, adult male and female longevity was longer when presented $B$. tabaci relative to $T$. vaporariorum, but a significant difference was not observed. Our results agree with previous reports indicating that the developmental period of $O$. strigicollis pre-adults is greater when they prey on $A$. cracivora than on C. cephalonica eggs (Amer et al. 2018). The same interaction was documented in numerous studies where the prey species strongly alter the developmental duration of pre-adults of genus Orius (Kim 1997; Kim 1999; Ohta 2001; Sengonca et al. 2008). Consequently, these fluctuations in the developmental period show that a prey species can strongly influence the developmental time of the pre-adult stages of $O$. strigicollis (Sengonca et al. 2008). The survival of $O$. strigicollis individuals was higher when fed on B. tabaci nymphs 
417 than T. vaporariorum. Amer et al. (2018) documented that higher mortality rates occurred in the

418 pre-adult stages of $O$. similis when they fed on $C$. cephalonica eggs compared to A. cracivora.

419 Similarly, the survival rate of O. laevigatus, O. niger, and O. majusculus individuals during

420 development was very low (i.e., high mortality rates) when fed eggs of E. kuehniella than those of

421 F. occidentalis (Kiman \& Yeargan 1985; Tommasini et al. 2004). Based on our results and those

422 of Arnó et al. (2008), the total developmental duration and survival of $O$. strigicollis nymphs, when

423 fed B. tabaci nymphs, were similar to those of O. majusculus and O. laevigatus. Arnó et al. (2008)

424 also reported results similar to those reported by Riudavets \& Castañé (1998), suggesting that

425 whitefly species could be considered suitable prey analogous to $F$. occidentalis larvae predated

426 upon by Orius spp. Furthermore, our results showed no significant difference in adult-pre-

427 oviposition period for both whitefly species. In contrast to our study, Zhang et al. (2012) found

428 that after mating, the development of the reproductive system of adult female $O$. similis took longer

429 (5-6 days) compared to our results. Similarly, the number of eggs laid by adult female $O$.

430 strigicollis were comparatively higher for both whitefly species than that of Tetranychus

431 cinnabarinus (Zhang et al. 2012).

432

Chen et al. (2017) found that intrinsic rate of increase $(r)$ is a key population parameter in

determining the development, growth, and survival of an organism. Southwood \& Henderson

434 (2009) also documented that greater values of $(r)$ i.e., $r>0$ highlight the fit of a prey with its host.

Comparing our result with these studies shows that the intrinsic rate of increase was more than (0)

and similar for both prey species. The net reproductive rate $\left(R_{0}\right)$ is also considered an important

population of an insect (Southwood \& Henderson 2009; Chen et al. 2017). Our results agree with 
440 In contrast to our study, low reproductive rates have been observed when $O$. strigicollis is fed $T$. 441 cinnabarinus (Zhang et al. 2012). The gross reproduction rate $(G R R)$ is thought to be a symbol of 442 a rapid increase of population, which is directly related to adult eclosion and the number of eggs 443 laid and hatched. All of these parameters can be significantly influenced by prey species (Cocuzza 444 et al. 1997; Huang \& Chi 2013). In our results, the highest GRR and greatest generation time (T) 445 occurred when $O$. strigicollis fed on $T$. vaporariorum when compared to B. tabaci. However, in 446 their study, Zhang et al. (2012) observed longer generation times at three constant temperatures 447 when individuals of $O$. similis preyed on T. cinnabarinus. species highlights its role as an effective biological control agent (Van Lenteren \& Woets 1988). Similarly, the searching ability and concomitance of predators and prey in space and time, are thought to be a crucial factor in successful biological control of a pest (Arnó et al. 2008). TrottinCaudal et al. (1991) and Montserrat (2001) both reported large populations of Orius spp. on vegetable crops where thrips and whiteflies coexist. Thus, it can be assumed that if $O$. strigicollis remains on the crop after suppression of the population of their desired prey, they can play a vital role in suppression of both whitefly species and could serve as an effective biological control agent. Supporting our hypothesis, Riudavets (2001) reported more than 20 Orius per cucumber 457 plant when the population of $F$. occidentalis was very low, which may have been due to the 458 presence of other pests. actively maintain strong populations when in the presence of species of whitefly such as $B$. tabaci and T. vaporariorum and could serve as a biological control agent in cotton fields and other vegetable crops, as well as in greenhouses where the populations of these species are destructive 
463 pests. The results obtained from laboratory experiments should be useful in understanding the 464 biology of $O$. strigicollis when in association with whitefly species, but field experiments will be 465 required to validate them.

466 Acknowledgments: The authors want to thank Miss. Abida Butt (Institute of Zoology, Punjab 467 University Lahore, Pakistan), Mirza Abid Mahmood (College of Plant Science and Technology, 468 Huazhong Agricultural University, Wuhan) and Fawad Zafar Ahmad Khan (Department of 469 Entomology, University of Georgia, U.S.A.) for technical assistance. The author acknowledge the 470 funding support granted by National Natural Science Foundation of China (Grant No. 31872023), 471 and The National Key R\&D Program of China (2017YFD0201000) for the current study.

\section{Reference}

473 Abrams PA. 1990. The effects of adaptive behavior on the type - 2 functional response. Ecology, $71: 877-885$.

475

476

477

Adly D. 2016. Use of Predators for Controlling the Whitefly, Bemisia tabaci Genn. and the Two Spotted Spider Mite, Tetranychus urticae Koch., in Cucumber Greenhouses in Egypt. Egyptian Journal of Biological Pest Control, 1:26.

Akca I, Ayvaz T, Yazici E, Smith CL, and Chi H. 2015. Demography and population projection of Aphis fabae (Hemiptera: Aphididae): with additional comments on life table research criteria. Journal of Economic Entomology, 108:1466-1478.

Akköprü EP, Atlihan R, Okut H, and Chi H. 2015. Demographic assessment of plant cultivar resistance to insect pests: a case study of the dusky-veined walnut aphid (Hemiptera: Callaphididae) on five walnut cultivars. Journal of Economic Entomology, 108:378-387. 
484 Ali, M., Naif, A.A., Huang, D., 2011. Prey consumption and functional response of a phytoseiid 485 predator, Neoseiulus womersleyi, feeding on spider mite, Tetranychus macfarlanei. Journal of Insect Science, 11:167.

487

488

489

490

491

492

493

494

495

496

497

498

499

500

501

502

503

504

Aljetlawi AA, Sparrevik E, and Leonardsson K. 2004. Prey-predator size - dependent functional response: derivation and rescaling to the real world. Journal of Animal Ecology, 73:239252.

Amer MES, Fu Y, and Niu L. 2018. Biological Aspects of Orius similis Zheng Reared on Two Preys at Three Constant Temperatures. Journal of Agricultural Science and Technology, $8: 350-363$.

Anderson PK, Cunningham AA, Patel NG, Morales FJ, Epstein PR, and Daszak P. 2004. Emerging infectious diseases of plants: pathogen pollution, climate change and agro-technology drivers. Trends in Ecology \& Evolution, 19:535-544.

Arnó J, Roig J, and Riudavets J. 2008. Evaluation of Orius majusculus and O. laevigatus as predators of Bemisa tabaci and estimation of their prey preference. Biological Control, $44: 1-6$.

Asare-Bediako E, Addo-Quaye A, and Bi-Kusi A. 2014. Comparative efficacy of plant extracts in managing whitefly (Bemisia tabaci Gen.) and leaf curl disease in okra (Abelmoschus esculentus L.). Am J. Agric Sci Technol 2:31-41.

Atlıhan R, Kaydan MB, Yarımbatman A, and Okut H. 2010. Functional response of the coccinellid predator Adalia fasciatopunctata revelierei to walnut aphid (Callaphis juglandis). Phytoparasitica, 38:23-29. 
505 Banihashemi AS, Seraj AA, Yarahmadi F, and Rajabpour A. 2017. Effect of host plants on 506 predation, prey preference and switching behavior of Orius albidipennis on Bemisia tabaci and Tetranychus turkestani. International Journal of Tropical Insect Science, 37:176-182.

508

509

510

511

512

513

514

515

516

517

518

519

520

521

522

523

524

525

526

Barboza NM, Esker P, Inoue - Nagata AK, and Moriones E. 2019. Genetic diversity and geographic distribution of Bemisia tabaci and Trialeurodes vaporariorum in Costa Rica. Annals of Applied Biology, 174:248-261.

Begon, Michael, John L. Harper, and Colin R. Townsend. Ecology. Individuals, populations and communities. Blackwell scientific publications, 1986.

Bonte J, De Hauwere L, Conlong D, and De Clercq P. 2015. Predation capacity, development and reproduction of the southern African flower bugs Orius thripoborus and Orius naivashae (Hemiptera: Anthocoridae) on various prey. Biological Control, 86:52-59.

Bonte M, and De Clercq P. 2011. Influence of predator density, diet and living substrate on developmental fitness of Orius laevigatus. Journal of Applied Entomology, 135:343-350.

Brown JK. 2007. The Bemisia tabaci complex: genetic and phenotypic variability drives begomovirus spread and virus diversification. Plant Disease, 1:25-56.

Butt A, and Xaaceph M. 2015. Functional response of Oxyopes javanus (Araneidae: Oxyopidae) to Sogatella furcifera (Hemiptera: Delphacidae) in laboratory and mesocosm. Pakistan Journal of Zoology, 1:47.

Carpintero DL. 2002. Catalogue of the Neotropical Anthocoridae (Heteroptera). Revista de la Sociedad Entomológica Argentina, 61:1-2.

Chen Q, Li N, Wang X, Ma L, Huang J-B, and Huang G-H. 2017. Age-stage, two-sex life table of Parapoynx crisonalis (Lepidoptera: Pyralidae) at different temperatures, PloS one 12:3. 
527 Chi H. 1988. Life-table analysis incorporating both sexes and variable development rates among individuals. Environmental Entomology, 17:26-34.

529 Chi H, and Liu H. 1985. Two new methods for the study of insect population ecology. Bull Inst $530 \quad$ Zool Acad Sin, 24:225-240.

531 Cocuzza G, De Clercq P, Lizzio S, Van De Veire M, Tirry L, Degheele D, and Vacante V. 1997. 532 Life tables and predation activity of Orius laevigatus and O. albidipennis at three constant temperatures. Entomologia Experimentalis et Applicate, 85:189-198.

534 Colvin J, Omongo C, Govindappa M, Stevenson PC, Maruthi M, Gibson G, Seal S, and Muniyappa V. 2006. Host - plant viral infection effects on arthropod - vector population growth, development and behaviour: management and epidemiological implications. Advances in virus research, 67:419-452.

538 Cook R, and Cockrell B. 1978. Predator ingestion rate and its bearing on feeding time and the theory of optimal diets. The Journal of Animal Ecology, 529-547.

De Barro P, Trueman J, and Frohlich D. 2005. Bemisia argentifolii is a race of $B$. tabaci (Hemiptera: Aleyrodidae): the molecular genetic differentiation of B. tabaci populations around the world. Bulletin of Entomological Research, 95:193-203.

543 De Barro PJ. 1995. Bemisia tabaci biotype B: a review of its biology, distribution and control. CSIRO Australia Division of Entomology Technical Paper, 36.

545 De Barro PJ, Driver F, Trueman JW, and Curran J. 2000. Phylogenetic relationships of world 546 populations of Bemisia tabaci (Gennadius) using ribosomal ITS1. Molecular Phylogenetics and Evolution, 16:29-36. 
548 Enkegaard A, Brødsgaard HF, and Hansen DL. 2001. Macrolophus caliginosus: functional response to whiteflies and preference and switching capacity between whiteflies and spider mites. Entomologia Experimentalis et Applicate, 101:81-88.

551 Farooq, M; Shakeel, M; Iftikhar, A; Shahid, M.R; Zhu X. 2018. Age-Stage, Two-Sex Life Tables of the Lady Beetle (Coleoptera: Coccinellidae) feeding on different aphid species. Journal of Economic Entomology, 2:111.

554

555

556

557

558

559

560

561

562

563

564

565

566

567

568

569

570

Fathipour Y, Hosseini A, Talebi AA, and Moharramipour S. 2006. Functional response and mutual interference of Diaeretiella rapae (Hymenoptera: Aphidiidae) on Brevicoryne brassicae (Homoptera: Aphididae). Entomologica Fennica, 17:90.

Fernández-arhex V, and Corley JC. 2003. The functional response of parasitoids and its implications for biological control. Biocontrol Science and Technology, 13:403-413.

Fritsche ME, and Tamo M. 2000. Influence of thrips prey species on the life - history and behaviour of Orius albidipennis. Entomologia Experimentalis et Applicata, 96:111-118.

Ganjisaffar F, and Perring TM. 2015. Prey stage preference and functional response of the predatory mite Galendromus flumenis to Oligonychus pratensis. Biological Control, $82: 40-45$

Gilbertson RL, Batuman O, Webster CG, and Adkins S. 2015. Role of the insect super vectors Bemisia tabaci and Frankliniella occidentalis in the emergence and global spread of plant viruses. Annual Review of Virology, 2:67-93.

Gitonga L, Löhr B, Overholt W, Magambo J, and Mueke J. 2002. Effect of temperature on the development of Orius albidipennis Reuter, a predator of the African legume flower thrips, Megalurothrips sjostedti Trybom. International Journal of Tropical Insect Science, $22: 215-220$. 
571 Goodman D. 1982. Optimal life histories, optimal notation, and the value of reproductive value. $572 \quad$ The American Naturalist, 119:803-823.

573 Gorman K, Devine G, Bennison J, Coussons P, Punchard N, and Denholm I. 2007. Report of

574

575

576

577

578

579

580

581

582

583

584

585

586

587

588

589

590

591

592

593 resistance to the neonicotinoid insecticide imidacloprid in Trialeurodes vaporariorum (Hemiptera: Aleyrodidae). Pest Management Science: formerly Pesticide Science, 63:555558.

Grenier S, and De Clercq P. 2003. Comparison of artificially vs. naturally reared natural enemies and their potential for use in biological control. Quality control and production of biological control agents: CABI Publishing, 115-131.

Haiyan H, Yuguo Z, Xingjun L, and Xingtian H. 2017. Different Effects on Growth Characteristics of Tobacco Plants Infested by Bemisia tabaci Biotype B and Trialeurodes vaporariorum. Chinese Agricultural Science Bulletin, 21.

Hasanzadeh H, Esfandiari M, Shishehbor P, and Rajabpour A. 2015. Functional response of different developmental stages of Orius albidipennis Reuter feeding on the strawberry spider mite, Tetranychus turkestani. Plant Protection, 38:3-13.

Huang Y.; Chi, H. 2011. The Age-Stage, Two-Sex Life Table with an Offspring Sex Ratio Dependent on Female Age. Journal of Agriculture \& Forestry., 60:337-345.

Hassell M. The spatial and temporal dynamics of host-parasitoid interactions. OUP Oxford; 2000 Jun 8 .

Hassell M, Lawton J, and Beddington J. 1976. The components of arthropod predation: I. The prey death-rate. The Journal of Animal Ecology, 135-164.

Hernández L. 1999. A review of the economically important species of the genus Orius (Heteroptera: Anthocoridae) in East Africa. Journal of Natural History, 33:543-568.

Peer] reviewing PDF | (2020:01:45107:2:0:NEW 13 Jun 2020) 
594 Herring JL. 1966. The genus Orius of the western hemisphere (Hemiptera: Anthocoridae). Annals 595 of the Entomological Society of America, 59:1093-1109.

596 Hodgson C, and Aveling C. 1988. Anthocoridae. Aphids, their biology, natural enemies and $597 \quad$ control, 2:279-292.

598 Holling CS. 1961. Principles of insect predation. Annual Review of Entomology, 6:163-182.

599 Holling CS. 1959. The components of predation as revealed by a study of small-mammal predation 600 of the European pine sawfly. The Canadian Entomologist, 91:293-320.

601 Holling CS. 1965. The functional response of predators to prey density and its role in mimicry and 602 population regulation. The Memoirs of the Entomological Society of Canada, 97:5-60.

603 Huang YB, and Chi H. 2012. Age - stage, two - sex life tables of Bactrocera cucurbitae 604 (Coquillett) (Diptera: Tephritidae) with a discussion on the problem of applying female 605 age - specific life tables to insect populations. Insect Science, 19:263-273.

606

607

608

609

610

611

612

613

614 615

Huang YB, and Chi H. 2013. Life tables of Bactrocera cucurbitae (Diptera: Tephritidae): with an invalidation of the jackknife technique. Journal of Applied Entomology, 137:327-339.

Jung, S., Yamada, K., Lee, S., 2013. Annotated catalog, biological notes and diagnoses of the flower bugs (Heteroptera: Anthocoridae sensu lato) in the Korean Peninsula. Journal of Asia-Pacific Entomology 16, 421-427.

Jiang Y, Wu Y, Duan Y, and Gao X. 2011. Control efficiencies of releasing Orius sauteri (Heteroptera: Anthocoridae) on some pests in greenhouse pepper. Chinese Journal of Biological Control, 27:414-417.

Jones DR. 2003. Plant viruses transmitted by whiteflies. European Journal of Plant Pathology, 109:195-219. 
616 Kageyama D, Narita S, Imamura T, and Miyanoshita A. 2010. Detection and identification of 617 Wolbachia endosymbionts from laboratory stocks of stored-product insect pests and their parasitoids. Journal of Stored Products Research, 46:13-19.

619 Karatolos N, Pauchet Y, Wilkinson P, Chauhan R, Denholm I, Gorman K, Nelson DR, Bass C, 620 and Williamson MS. 2011. Pyrosequencing the transcriptome of the greenhouse whitefly, Trialeurodes vaporariorum reveals multiple transcripts encoding insecticide targets and detoxifying enzymes. BMC genomics, 12:56.

623

624

625

626

627

628

629

630

631

632

633

634

635

636

637

638

Khan I, and Wan F. 2015. Life history of Bemisia tabaci (Gennadius) (Homoptera: Aleyrodidae) biotype B on tomato and cotton host plants. J. Entomol. Zool. Stud, 3:117-121.

Kim J. 1997. Development and oviposition of Orius strigicollis (Poppius) (Hemiptera: Anthocoridae) reared on three different insect preys. Korean Journal of Applied Entomology, 36:166-171.

Kim J. 1999. Effect of temperature on the development and oviposition of minute pirate bug, Orius strigicollies (Hemiptera: Anthocoridae). Korean Jouranl of Applied Entomology, 38:2933.

Kiman Z, and Yeargan K. 1985. Development and reproduction of the predator Orius insidiosus (Hemiptera: Anthocoridae) reared on diets of selected plant material and arthropod prey. Annals of the Entomological Society of America, 78:464-467.

Lapidot M, Legg JP, Wintermantel WM, and Polston JE. 2014. Management of whiteflytransmitted viruses in open-field production systems. Advances in virus research: Elsevier, 147-206.

Livdahl TP, and Stiven AE. 1983. Statistical difficulties in the analysis of predator functional response data. The Canadian Entomologist, 115:1365-1370. 
639 López YIÁ, Martínez-Gallardo NA, Ramírez-Romero R, López MG, Sánchez-Hernández C, and 640 Délano-Frier JP. 2012. Cross-kingdom effects of plant-plant signaling via volatile organic

641

642

643

644

645

646

647

648

649

650

651

652

653

654

655

656

657

658

659

660

661 compounds emitted by tomato (Solanum lycopersicum) plants infested by the greenhouse whitefly (Trialeurodes vaporariorum). Journal of Chemical Ecology, 38:1376-1386.

Madadi H, Enkegaard A, Brodsgaard H, Kharrazi - Pakdel A, Mohaghegh J, and Ashouri A. 2007. Host plant effects on the functional response of Neoseiulus cucumeris to onion thrips larvae. Journal of Applied Entomology, 131:728-733.

Martin JH, Mifsud D, and Rapisarda C. 2000. The whiteflies (Hemiptera: Aleyrodidae) of Europe and the Mediterranean basin. Bulletin of Entomological Research, 90:407-448.

Montserrat M. 2001. Estudi de la relació depredador-presa en alguns heteròpters presents en el cultiu de cogombre. Phd Thesis, University of Lleida.

Montserrat M, Albajes R, and Castañé C. 2000. Functional response of four heteropteran predators preying on greenhouse whitefly (Homoptera: Aleyrodidae) and western flower thrips (Thysanoptera: Thripidae). Environmental Entomology, 29:1075-1082.

Navas-Castillo J, Fiallo-Olivé E, and Sánchez-Campos S. 2011. Emerging virus diseases transmitted by whiteflies. Annual Review of Phytopathology, 49:219-248.

Omkar, P.A., and Pervez, A. 2004. Functional and numerical responses of Propylea dissecta (Col., Coccinellidae). Journal of Applied Entomology, 128:140-146.

Ohta I. 2001. Effect of temperature on development of Orius strigicollis (Heteroptera: Anthocoridae) fed on Frankliniella occidentalis (Thysanoptera: Thripidae). Applied Entomology and Zoology, 36:483-488.

Opit G, Roitberg B, and Gillespie D. 1997. The functional response and prey preference of Feltiella acarisuga (Vallot) (Diptera: Cecidomyiidae) for two of its prey: male and female 
662 663 664 665 666 667 668 669

twospotted spider mites, Tetranychus urticae Koch (Acari: Tetranychiidae). The Canadian Entomologist, 129:221-227.

Pervez A. 2005. Functional responses of coccinellid predators: an illustration of a logistic approach. Journal of Insect Science, 5:5.

Pervez, A. OMKAR 2003: Predation potential and handling time estimates of a generalist aphidophagous ladybird, Propylea dissecta. Biol. Mem., 29:91-97.

Pimentel D, Lach L, Zuniga R, and Morrison D. 2000. Environmental and economic costs of nonindigenous species in the United States. BioScience, 50:53-66.

Polston JE, De Barro P, and Boykin LM. 2014. Transmission specificities of plant viruses with the newly identified species of the Bemisia tabaci species complex. Pest management science, $70: 1547-1552$.

Postle AC, Steiner MY, and Goodwin S. 2001. Oriini (Hemiptera: Anthocoridae) new to Australia. Australian Journal of Entomology, 40:231-244.

Prijović M, Marčić D, Drobnjaković T, Međo I, and Perić P. 2013. Life history traits and population growth of greenhouse whitefly (Trialeurodes vaporariorum Westwood) on different tomato genotypes. Pesticidi i Fitomedicina,ss 28:239-245.

Pru Epa, Atlihan R, Okut H, and Chi H. 2015. Demographic Assessment of Plant Cultivar Resistance to Insect Pests: A Case Study of the Dusky-Veined Walnut Aphid (Hemiptera: Callaphididae) on Five Walnut Cultivars. Journal of Economic Entomology, 108:378-387.

Riechert S, and Harp J. 1987. Nutritional ecology of spiders. In 'Nutritional Ecology of Insects, Mites, Spiders and Related Invertebrates’. (Eds F. Slansky Jr and JR Rodriguez.) 645-672. John Wiley and Son: New York. 
684 Pym, A., Singh, K.S., Nordgren, A., Davies, T.E., Zimmer, C.T., Elias, J., Slater, R. and Bass, C., 685 2019. Host plant adaptation in the polyphagous whitefly, Trialeurodes vaporariorum, is

686 associated with transcriptional plasticity and altered sensitivity to insecticides. $B M C$

687 genomics, 20:1-19.

688

689

690

691

692

693

694

695

696

697

698

699

700

701

702

703

704

705

706

Riudavets J. 2001. Depredadors autòctons per al control biològic de Frankliniella occidentalis (Thysanoptera: Thripidae) en conreus hortícoles. Universitat de Lleida.

Riudavets J, and Castañé C. 1998. Identification and evaluation of native predators of Frankliniella occidentalis (Thysanoptera: Thripidae) in the Mediterranean. Environmental Entomology, 27:86-93.

Rocha Ld, and Redaelli LR. 2004. Functional response of Cosmoclopius nigroannulatus (Hem. Reduviidae) to different densities of Spartocera dentiventris (Hem. Coreidae) nymphae. Brazilian Journal of Biology, 64:309-316.

Rutledge CE, and O’Neil RJ. 2005. Orius insidiosus (Say) as a predator of the soybean aphid, Aphis glycines Matsumura. Biological Control, 33:56-64.

Sakaki S, and Sahragard A. 2011. A new method to study the functional response of Scymnus syriacus (Coleoptera: Coccinellidae) to different densities of Aphis gossypii. Journal of Asia-Pacific Entomology, 14:459-462.

Sengonca C, Ahmadi K, and Blaeser P. 2008. Biological characteristics of Orius similis Zheng (Heteroptera, Anthocoridae) by feeding on different aphid species as prey. Journal of Plant Diseases and Protection, 115:32-38.

Shaaya E, Kostjukovski M, Eilberg J, and Sukprakarn C. 1997. Plant oils as fumigants and contact insecticides for the control of stored-product insects. Journal of Stored Products Research, 33:7-15. 
707 Shahpouri A, Yarahmadi F, and Sohani NZ. 2019. Functional response of the predatory species 708 Orius albidipennis Reuter (Hemiptera: Anthocoridae) to two life stages of Bemisia tabaci (Genn.)(Hemiptera: Aleyrodidae). Egyptian Journal of Biological Pest Control, 29:14.

710

711

712

713

714

715

716

717

718

719

720

721

722

723

724

725

726

727

728

729
Simmonds M, Manlove J, Blaney W, and Khambay B. 2002. Effects of selected botanical insecticides on the behaviour and mortality of the glasshouse whitefly Trialeurodes vaporariorum and the parasitoid Encarsia formosa. Entomologia Experimentalis et Applicata, 102:39-47.

Southwood, T.R.E. and Henderson, P.A., 2009. Ecological methods. John Wiley \& Sons.

Stephens, D.W. and Krebs, J.R., 1986. Foraging theory (Vol. 1). Princeton University Press.

Tomar S, Sharma S, and Malik K. 2017. Life parameters of whitefly (Bemisia tabaci, Genn.) on different host plants. Indian Journal of Scientific Research, 34-38.

Tommasini MG, Van Lenteren JC, and Burgio G. 2004. Biological traits and predation capacity of four Orius species on two prey species. Bulletin of Insectology, 57:79-93.

Trottin-Caudal Y, Grasselly D, Trapateau M, Dobelin H, and Millot P. 1991. Biological control of Frankliniella occidentalis with Orius majusculus on cucumber. Bulletin OILB SROP (France).

Tuan SJ, Yeh CC, Atlihan R, and Chi H. 2016. Linking Life Table and Predation Rate for Biological Control: A Comparative Study of Eocanthecona furcellata (Hemiptera: Pentatomidae) Fed on Spodoptera litura (Lepidoptera: Noctuidae) and Plutella xylostella (Lepidoptera: Plutellidae). Journal of Economic Entomology 109:13-24.

Trexler, J.C., and Travis, J. (1993). Nontraditional Regression Analyses. Ecology 74, 1629-1637.

Trexler, J. C., McCulloch, C. E., \& Travis, J. (1988). How can the functional reponse best be determined? Oecologia, 76:206-214.

Peer] reviewing PDF | (2020:01:45107:2:0:NEW 13 Jun 2020) 
730 Van Alphen, J.J.M. and Jervis, M.A., 1996. Foraging behaviour. In Insect natural enemies, 1-62.

$731 \quad$ Springer, Dordrecht.

732 Van Lenteren JC, and Bueno VH. 2003. Augmentative biological control of arthropods in Latin 733 America. BioControl, 48:123-139.

734 Varshney, R., Budhlakoti, N., and Ballal, C.R. 2018. Functional response of Geocoris ochropterus

735 Fieber (Hemiptera: Geocoridae) to different egg densities of Helicoverpa armigera 736 (Hübner) (Lepidoptera: Noctuidae). Phytoparasitica, 46:451-458.

737 Van Lenteren Je, and Woets Jv. 1988. Biological and integrated pest control in greenhouses. 738 Annual Review of Entomology, 33:239-269.

739 Veeravel, R., Baskaran, P., 1997. Functional and numerical Responses of Coccinella transversalis 740 Fab. and Cheilomenes sexmaculatus Fab. feeding on the Melon Aphid, Aphis gossypii 741 Glov. International Journal of Tropical Insect Science, 17:335-339.

742 Wang S-x, Di N, Chen X, Zhang F, Biondi A, Desneux N, and Wang S. 2019. Life history and 743 functional response to prey density of the flower bug Orius sauteri attacking the fungivorous sciarid fly Lycoriella pleuroti. Journal of Pest Science, 92:715-722.

745

746

747

748

749

750

751

752
Wei Q, Wang C, Zhang W, and Liu H. 2018. The pattern of tobacco whitefly, Trialeurodes vaporariorum occurrence and spreading in Chongqing Area. Journal of Environmental Entomology, 40:571-578.

Wiedenmann RN, and O'Neil RJ. 1991. Laboratory measurement of the functional response of Podisus maculiventris (Say) (Heteroptera: Pentatomidae). Environmental Entomology, 20:610-614.

Wisler G, Duffus J, Liu H-Y, and Li R. 1998. Ecology and epidemiology of whitefly-transmitted closteroviruses. Plant Disease, 82:270-280. 
753 Wraight, S.P., Lopes, R.B. and Faria, M., 2017. Microbial control of mite and insect pests of 754 greenhouse crops. In Microbial control of insect and mite pests, 237-252. Academic Press.

755 Yamada K, Yasunaga T, and Artchawakom T. 2016. The flower bug genus Orius wolff, 1811

756 (Hemiptera: heteroptera: Anthocoridae: oriini) of Thailand. Journal of Natural History $757 \quad 50: 1103-1157$.

758 Yang FL, Zhu F, and Lei CL. 2012. Insecticidal activities of garlic substances against adults of 759 grain moth, Sitotroga cerealella (Lepidoptera: Gelechiidae). Insect Science, 19:205-212.

Yasunaga, T., 1997. The Flower Bug Genus Orius WOLFF (Heteroptera: Anthocoridae) from 761 Japan and Taiwan, Part III. Applied Entomology and Zoology 32, 387-394.

762

763

764

765

766

767

768

769

770

771

772

773

774

Yazdani M, and Keller M. 2016. The shape of the functional response curve of Dolichogenidea tasmanica (Hymenoptera: Braconidae) is affected by recent experience. Biological Control 97:63-69.

Yazdani M, and Zarabi M. 2011. The effect of diet on longevity, fecundity, and the sex ratio of Clitostethus arcuatus (Rossi) (Coleoptera: Coccinellidae). Journal of Asia-Pacific Entomology 14:349-352.

Yin J, Gao X, Wu Y, Jiang Y, Liu S, Duan A, Zhang Z, and Liu C. 2013. Thrips control on the greenhouse eggplant by releasing Orius sauteri (Heteroptera: Anthocoridae). Chinese Journal of Biological Control, 29:459-462.

Yoza K-i, Imamura T, Kramer KJ, MORGAN TD, Nakamura S, Akiyama K, Kawasaki S, Takaiwa F, and OHTSUBO Ki. 2005. Avidin expressed in transgenic rice confers resistance to the stored-product insect pests Tribolium confusum and Sitotroga cerealella. Bioscience, Biotechnology, and Biochemistry 69:966-971. 
775 Zamani A, Talebi A, Fathipour Y, and Baniameri V. 2006. Temperature-dependent functional

776

777

778

779

780

781

782

783

784

785

786

787

788

789

790

791

792

793 response of two aphid parasitoids, Aphidius colemani and Aphidius matricariae (Hymenoptera: Aphidiidae), on the cotton aphid. Journal of Pest Science 79:183-188.

Zandi-Sohani N, Rajabpour A, Yarahmadi F, and Ramezani L. 2018. Sensitivity of Bemisia tabaci (Hemiptera: Aleyrodidae) and the Generalist Predator Orius albidipennis (Hemiptera: Anthocoridae) to Vapors of Essential Oils. Journal of Entomological Science, 53:493-502.

Zhang S-C, Zhu F, Zheng X-L, Lei C-L, and Zhou X-M. 2012. Survival and developmental characteristics of the predatory bug Orius similis (Hemiptera: Anthocoridae) fed on Tetranychus cinnabarinus (Acari: Tetranychidae) at three constant temperatures. European Journal of Entomology, 4:109.

Zhao J, Guo X, Tan X, Desneux N, Zappala L, Zhang F, and Wang S. 2017. Using Calendula officinalis as a floral resource to enhance aphid and thrips suppression by the flower bug Orius sauteri (Hemiptera: Anthocoridae). Pest Management Science 73:515-520.

Zhou X-M, Zhu F, Li H, and Lei C-L. 2006. Effect of temperature on development of Orius similis Zheng (Hemiptera: Anthocoridae) and on its predation activity against Aphis gossypii Glover (Hemiptera: Aphididae). Pan Pacific Entomologist 82:97-102.

Zhou X, and Lei C. 2002. Utilization efficiency and functional response of Orius similis Zheng (Hemiptera: Anthocoridae) to different preys. Acta Ecologica Sinica 22:2085-2090. 


\section{Table $\mathbf{1}$ (on next page)}

Results of logistic regression for different life stages of $O$. strigicollis against different prey densities

The negative values of linear coefficient for both life stages of $O$. strigicollis fed on different densities of two whitefly species described type II functional response curve. $P$-value $\leq 0.05$ is considered as significant. Goodness of fit test with $p$-value $\geq 0.05$ is best fitted. 
Table1: Results of logistic regression for different life stages of $O$. strigicollis against different prey densities.

\begin{tabular}{|c|c|c|c|c|c|c|c|c|c|}
\hline \multirow{2}{*}{ Prey specie } & \multirow{2}{*}{ Parameters } & \multicolumn{2}{|c|}{ Estimates } & \multicolumn{2}{|c|}{ S.E. } & \multicolumn{2}{|c|}{ Z-value } & \multicolumn{2}{|c|}{ P-value } \\
\hline & & $3^{\text {rd }}$ instar & Adult & $3^{\text {rd }}$ instar & Adult & $3^{\text {rd }}$ instar & Adult & $3^{\text {rd }}$ instar & Adult \\
\hline \multirow{7}{*}{ B. tabaci } & Intercept & 8.1005 & 6.4071 & 1.937 & 1.916 & 4.18 & 3.34 & 0.000 & 0.001 \\
\hline & Linear & -2.024 & -1.3928 & 0.664 & 0.661 & -3.05 & -2.11 & 0.002 & 0.035 \\
\hline & Quadratic & 0.1832 & 0.1176 & 0.072 & 0.072 & 2.55 & 1.64 & 0.011 & 0.102 \\
\hline & Cubic & -0.0058 & -0.0037 & 0.002 & 0.002 & -2.33 & -1.48 & 0.02 & 0.139 \\
\hline & \multicolumn{9}{|c|}{ Goodness-of-Fit } \\
\hline & Deviance & 3.0612 & 1.7498 & & & & & 0.216 & 0.417 \\
\hline & $\begin{array}{c}\text { Hosmer- } \\
\text { Lemeshow }\end{array}$ & 3.0418 & 1.7443 & & & & & 0.551 & 0.783 \\
\hline \multirow{7}{*}{$\begin{array}{c}T . \\
\text { vaporariorum }\end{array}$} & Intercept & 3.5934 & 4.3138 & 1.524 & 1.918 & 2.36 & 2.25 & 0.018 & 0.025 \\
\hline & Linear & -0.7081 & -0.5958 & 0.548 & 0.668 & -1.29 & -0.89 & 0.197 & 0.373 \\
\hline & Quadratic & 0.0532 & 0.0341 & 0.061 & 0.073 & 0.87 & 0.47 & 0.387 & 0.64 \\
\hline & Cubic & -0.0016 & -0.001 & 0.002 & 0.003 & -0.74 & -0.38 & 0.461 & 0.704 \\
\hline & \multicolumn{9}{|c|}{ Goodness-of-Fit } \\
\hline & Deviance & 0.3479 & 0.5546 & & & & & 0.84 & 0.758 \\
\hline & $\begin{array}{l}\text { Hosmer- } \\
\text { Lemeshow }\end{array}$ & 0.3487 & 0.5593 & & & & & 0.986 & 0.967 \\
\hline
\end{tabular}

The negative values of linear coefficient for both life stages of $O$. strigicollis fed on different densities of two whitefly species described type II functional response curve. $P$-value $\leq 0.05$ is considered as significant. Goodness of fit test with $p$-value $\geq 0.05$ is best fitted. 


\section{Table 2 (on next page)}

Parameter estimates from Holling's Disc equation for a Type II functional response

No significant difference in $T_{h}$ and $T / T_{h}$ were estimated for third instar nymphs of $O$.

strigicollis. However, it was shortest and maximum when adult female fed on $T$. vaporariorum respectively. No significant difference recorded in coefficient of attack rate $(\alpha)$ for both prey species. 
1 Table 2: Parameter estimates from Holling's Disc equation for a Type II functional response.

\begin{tabular}{ccccc}
\hline Parameters & \multicolumn{2}{c}{ 3 $^{\text {rd }}$ instar } & \multicolumn{2}{c}{ Adult } \\
\cline { 2 - 5 } & B. tabaci & T. vaporariorum & B. tabaci & T. vaporariorum \\
\hline Handling Time $\left(\mathrm{T}_{\mathrm{h}}\right)$ & 2.453 & 2.443 & 2.158 & 1.752 \\
Attack rate $(\alpha)$ & 0.063 & 0.052 & 0.059 & 0.054 \\
Max. predation rate $\left(\mathrm{T} / \mathrm{T}_{\mathrm{h}}\right)$ & 9.78 & 9.82 & 11.12 & 13.70 \\
\hline
\end{tabular}

2 No significant difference in $\mathrm{T}_{\mathrm{h}}$ and $\mathrm{T} / \mathrm{T}_{\mathrm{h}}$ were estimated for third instar nymphs of $O$. strigicollis. However, 3 it was shortest and maximum when adult female fed on $T$. vaporariorum respectively. No significant $4 \quad$ difference recorded in coefficient of attack rate $(\alpha)$ for both prey species.

5 


\section{Table 3 (on next page)}

Functional response parameters of different life stages of $O$. strigicollis to different densities of $B$. tabaci and $T$. vaporariorum

The $T_{h}$ for third instar nymphs and adult females of $O$. strigicollis increased with increasing prey densities. However, the searching time and searching efficiency show an inverse relationship with both prey densities. The attack rates of both life stages of $O$. strigicollis were similar with no significant differences at different densities of both prey species. 
Table 3: Functional response parameters of different life stages of $O$. strigicollis

to different densities of B. tabaci and T. vaporariorum.

\begin{tabular}{|c|c|c|c|c|c|c|c|c|c|}
\hline \multirow{2}{*}{ Prey Species } & \multirow{2}{*}{ Prey density } & \multicolumn{2}{|c|}{ Total handling time $\left(T_{h}\right)$} & \multicolumn{2}{|c|}{ Total search time (Ts) } & \multicolumn{2}{|c|}{ Attack rate (a) } & \multicolumn{2}{|c|}{ Search efficiency (E) } \\
\hline & & $3^{\text {rd }}$ Instar & Adult & $3^{\text {rd }}$ Instar & Adult & $3^{\text {rd }}$ Instar & Adult & $3^{\text {rd }}$ Instar & Adult \\
\hline \multirow[t]{6}{*}{ B. tabaci } & 4 & 9.2 & 8.1 & 14.8 & 15.9 & 0.064 & 0.075 & 0.94 & 0.93 \\
\hline & 6 & 11.3 & 10.4 & 12.7 & 13.6 & 0.060 & 0.070 & 0.77 & 0.80 \\
\hline & 8 & 12.1 & 12.3 & 11.1 & 11.7 & 0.059 & 0.071 & 0.66 & 0.71 \\
\hline & 10 & 15.5 & 14.3 & 8.5 & 9.7 & 0.075 & 0.069 & 0.63 & 0.66 \\
\hline & 12 & 15.6 & 14.4 & 8.4 & 9.6 & 0.063 & 0.058 & 0.53 & 0.56 \\
\hline & 14 & 16.0 & 14.5 & 8.0 & 9.5 & 0.059 & 0.051 & 0.47 & 0.48 \\
\hline \multirow[t]{6}{*}{$\begin{array}{c}T . \\
\text { vaporariorum }\end{array}$} & 4 & 8.1 & 6.5 & 15.9 & 17.5 & 0.053 & 0.053 & 0.83 & 0.93 \\
\hline & 6 & 10.3 & 8.8 & 13.7 & 15.2 & 0.055 & 0.055 & 0.70 & 0.84 \\
\hline & 8 & 12.5 & 11.0 & 11.5 & 13.0 & 0.060 & 0.060 & 0.64 & 0.78 \\
\hline & 10 & 13.6 & 12.2 & 10.4 & 11.8 & 0.059 & 0.059 & 0.56 & 0.70 \\
\hline & 12 & 14.6 & 12.6 & 9.4 & 11.4 & 0.052 & 0.052 & 0.50 & 0.60 \\
\hline & 14 & 14.8 & 12.5 & 9.2 & 11.5 & 0.044 & 0.044 & 0.43 & 0.51 \\
\hline
\end{tabular}




\section{Table 4 (on next page)}

Effects of whitefly species as prey on biological traits of $O$. strigicollis

The developmental time for N1, N2 and N4 was significantly higher when fed on T. vaporariorum. However, no significant difference recorded in adult longevity. SEs were estimated using 100,000 bootstrap. Means marked with multiple letters in the same row symbolize the significant difference using a pair bootstrap test. $P<0.05$. 
Table 4: Effects of whitefly species as prey on biological traits of O. strigicollis

\begin{tabular}{ccc}
\hline Life Stages & B. tabaci & T. vaporariorum \\
\hline & Mean \pm S.E. & Mean \pm S.E. \\
Egg duration (d) & $3.00 \pm 0.00 \mathrm{a}$ & $3.00 \pm 0.00 \mathrm{a}$ \\
N1 duration(d) & $2.10 \pm 0.06 \mathrm{~b}$ & $2.30 \pm 0.09 \mathrm{a}$ \\
N2 duration (d) & $3.24 \pm 0.08 \mathrm{~b}$ & $3.80 \pm 0.09 \mathrm{a}$ \\
N3 duration (d) & $3.00 \pm 0.00 \mathrm{a}$ & $2.96 \pm 0.10 \mathrm{~b}$ \\
N4 duration (d) & $2.15 \pm 0.46 \mathrm{~b}$ & $2.42 \pm 0.01 \mathrm{a}$ \\
N5 duration (d) & $3.65 \pm 0.49 \mathrm{a}$ & $3.71 \pm 0.14 \mathrm{a}$ \\
Male adult longevity (d) & $11.67 \pm 1.45 \mathrm{a}$ & $11.33 \pm 1.52 \mathrm{a}$ \\
Female adult longevity (d) & $15.47 \pm 1.30 \mathrm{a}$ & $13.82 \pm 1.86 \mathrm{a}$ \\
\hline The developmental time for N1, N2 and N4 was significantly higher when fed on T. vaporariorum. \\
However, no significant difference recorded in adult longevity. SEs were estimated using 100,000 \\
bootstrap. Means marked with multiple letters in the same row symbolize the significant difference \\
using a pair bootstrap test. $P<0.05$.
\end{tabular}

6 


\section{Table 5 (on next page)}

Effects of whitefly species as prey on biological traits of $O$. strigicollis

SEs were estimated using 100,000 bootstrap. Means marked with multiple letters in the same row symbolize the significant difference using a pair bootstrap test. $P<0.05$. APOP: Adult pre-oviposition period of female adult. TPOP: Adult pre-oviposition period of female counted from the birth. 
Table 5: Effects of whitefly species as prey on biological traits of $O$. strigicollis

\begin{tabular}{ccc}
\hline Parameters & B. tabaci & T. vaporariorum \\
\hline & Mean \pm S.E. & Mean \pm S.E. \\
APOP (d) & $2.35 \pm 0.15 \mathrm{a}$ & $2.4 \pm 0.22 \mathrm{a}$ \\
TPOP (d) & $19.82 \pm 0.81 \mathrm{~b}$ & $20.5 \pm 0.22 \mathrm{a}$ \\
Oviposition (d) & $8.29 \pm 0.83 \mathrm{a}$ & $7.80 \pm 1.31 \mathrm{a}$ \\
Fecundity (F) (eggs /female) & $54.18 \pm 10.52 \mathrm{a}$ & $49.82 \pm 15.81 \mathrm{a}$ \\
Sex ratio (F : M) & $17: 9$ & $11: 6$ \\
\hline
\end{tabular}

2 SEs were estimated using 100,000 bootstrap. Means marked with multiple letters in the same row symbolize the

3 significant difference using a pair bootstrap test. $P<0.05$. APOP: Adult pre-oviposition period of female adult. 4 TPOP: Adult pre-oviposition period of female counted from the birth.

5

6 


\section{Table 6(on next page)}

Population parameters of 0 . strigicollis

The values of $r, \lambda$ and $R_{0}$ were maximum when predatory bug fed on $B$. tabaci nymphs. However, $T$ and GRR increased when $O$. strigicollis fed on $T$. vaporariorum. SEs were estimated using 100,000 bootstraps. Means marked with different letters in the same row symbolize the significant difference using a pair bootstrap test. $P<0.05$. 
Table 6: Population parameters of $O$. strigicollis

\begin{tabular}{ccc}
\hline Parameters & $\begin{array}{c}\text { B. tabaci } \\
\text { (Mean } \pm \text { S.E.) }\end{array}$ & $\begin{array}{c}\text { T. vaporariorum } \\
\text { (Mean } \pm \text { S.E.) }\end{array}$ \\
\hline Intrinsic rate of increase $(r)\left(\mathrm{d}^{-1}\right)$ & $0.1345 \pm 0.0093 \mathrm{a}$ & $0.1092 \pm 0.0147 \mathrm{a}$ \\
Rate of increase $(\lambda)\left(\mathrm{d}^{-1}\right)$ & $1.1439 \pm 0.0106 \mathrm{a}$ & $1.1153 \pm 0.0162 \mathrm{a}$ \\
$\quad \begin{array}{c}\text { Net reproductive rate }\left(R_{0}\right) \\
\text { (offspring/individual) }\end{array}$ & $30.70 \pm 7.5818 \mathrm{a}$ & $18.2667 \pm 7.0703 \mathrm{a}$ \\
$\quad \begin{array}{c}\text { Generation time }(T)(\text { days) } \\
\text { Gross reproduction rate }(G R R)\end{array}$ & $25.464 \pm 0.428 \mathrm{a}$ & $26.611 \pm 0.753 \mathrm{a}$ \\
$\quad$ (Offspring) & $54.62 \pm 12.777 \mathrm{a}$ & $61.57 \pm 20.215 \mathrm{a}$ \\
\hline
\end{tabular}

The values of $r, \lambda$ and $R_{0}$ were maximum when predatory bug fed on B. tabaci nymphs. However, $T$ and GRR increased when $O$. strigicollis fed on $T$. vaporariorum. SEs were estimated using 100,000 bootstraps. Means marked with different letters in the same row symbolize the significant difference using a pair bootstrap test. $P$ $<0.05$. 
Figure 1

Functional response of life stages of $O$. strigicollis to different densities of whitefly species

Each data point represents the observed number of whitefly nymphs. The functional response curves of different life stages of $O$. strigicollis to third instar nymphs of $B$. tabaci (A $\& B$ ) and $T$. vaporariorum $(C \& D)$ at different densities shown type II functional response. The number of nymphs of both prey species consumed by $O$. strigicollis increased with increases in the prey density from 4 to 8 nymphs per predator, but plateaued with no significant increase in prey consumption with densities of more than 8 nymphs per predator.
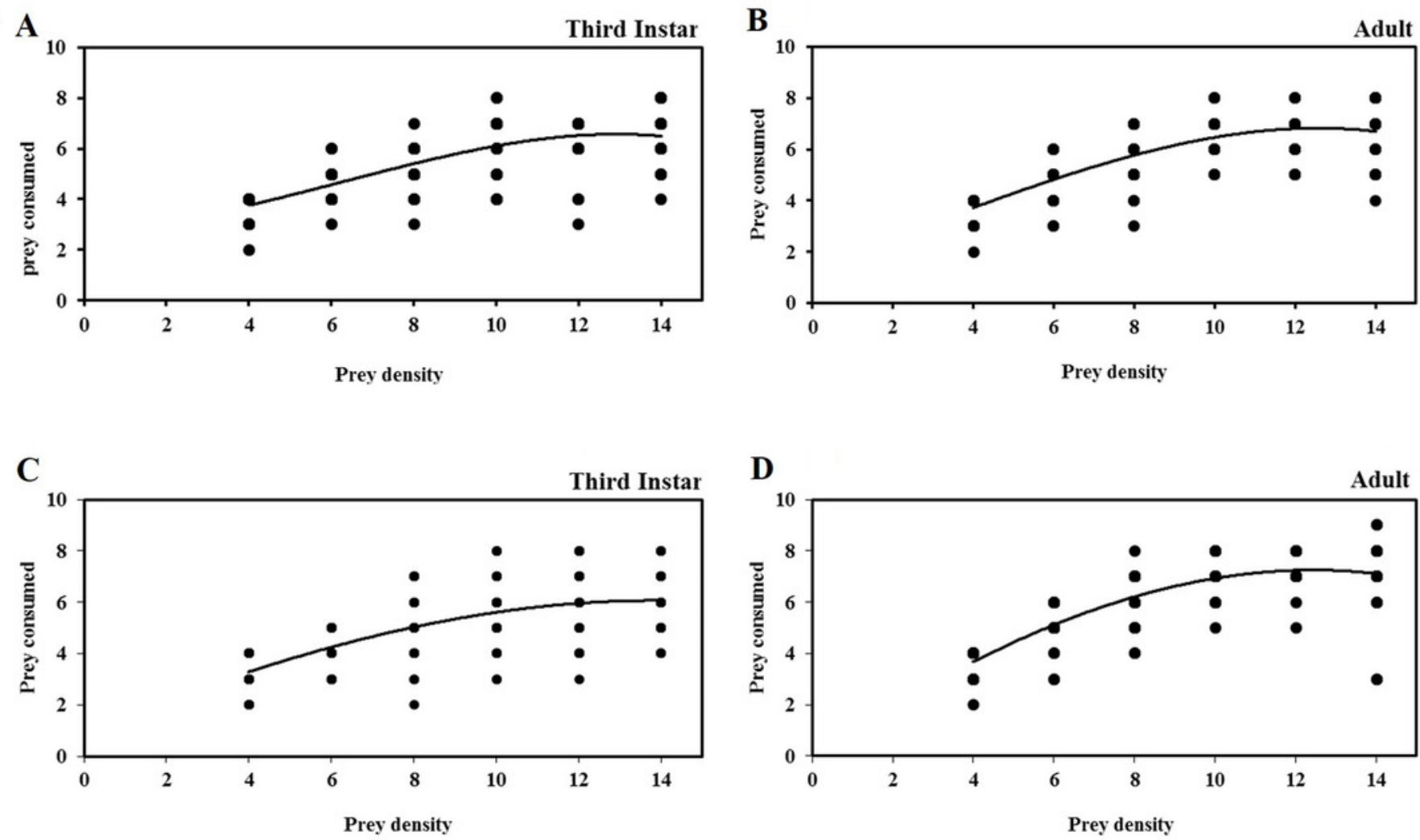
Figure 2

Age-stage specific survival rate $\left(S_{x j}\right)$ of $O$. strigicollis when offered with whitefly species

The overlap occurs between stages as a result of variations in the developmental rate of individuals. When fed nymphs of $B$. tabaci (A), more eggs of $O$. strigicollis successfully survived and reached to the adult stage. However, the survival rate was significantly lower when O. strigicollis were fed T. vaporariorum (B) nymphs.

A

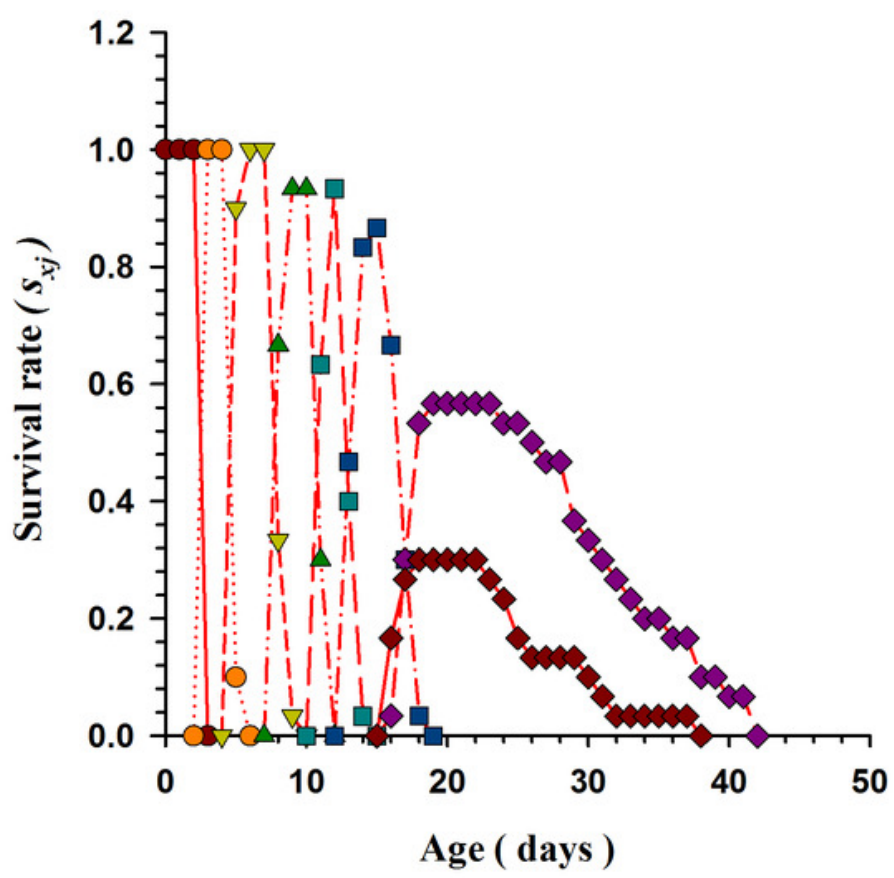

B

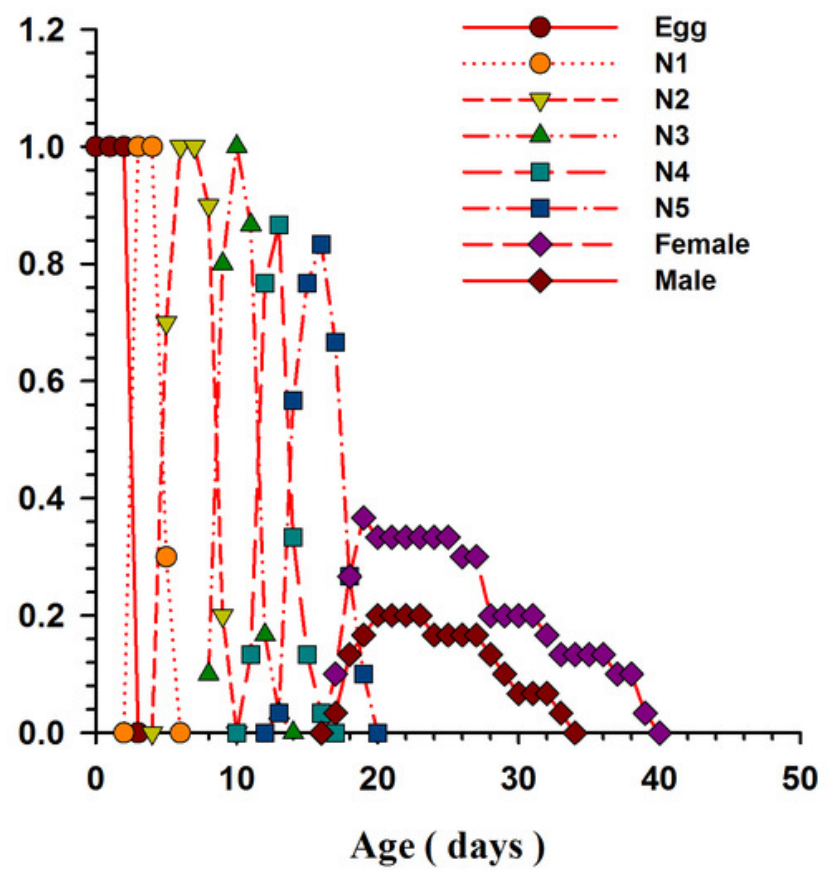


Figure 3

The $I_{x}, f_{x}, m_{x}$, and $l_{x} m_{x}$ of $O$. strigicollis presented with $B$. tabaci $(\mathrm{A}) \& T$. vaporariorum $(\mathrm{B})$

As age increased, the $I_{x}$ of $O$. strigicollis decreased and showed an inverse relationship for both prey species. The peak of the $m x$ and $f x$ curve obtained when $O$. strigicollis fed on $B$. tabaci.

$I_{x}$ : Age-specific survival rate $f_{x}$ : female age-specific fecundity $m_{x}$ : age-specific fecundity of the total population $I_{x} m_{x}$ : and age-specific maternity
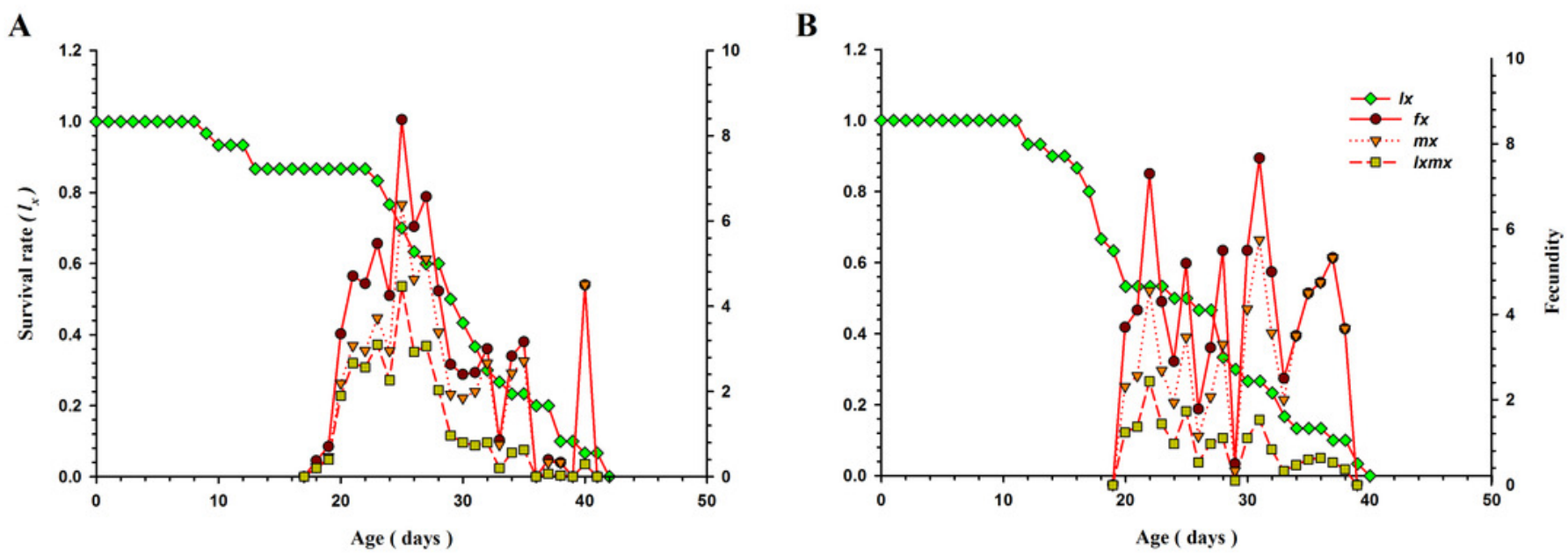
Figure 4

Age-specific life expectancy $\left(e_{x j}\right)$ of $O$. strigicollis offered with whiteflies species

The life expectancy of a newborn $O$. strigicollis egg was greater when fed nymphs of $B$. tabaci (A) than those of T. vaporariorum (B).

A

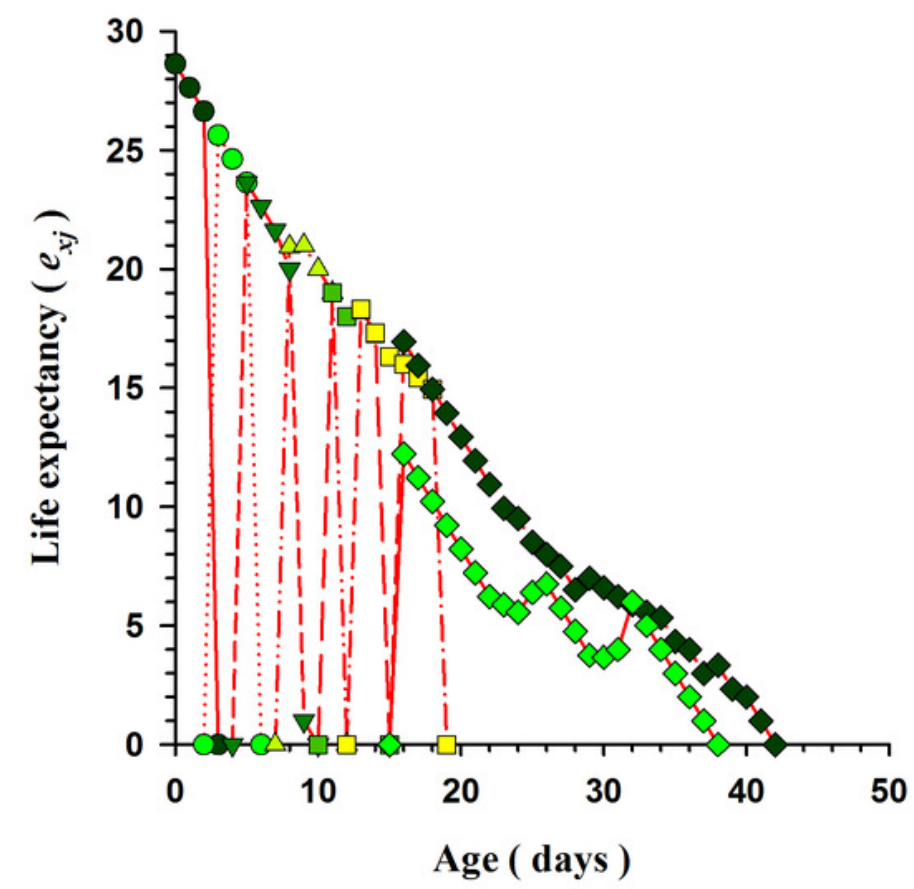

B

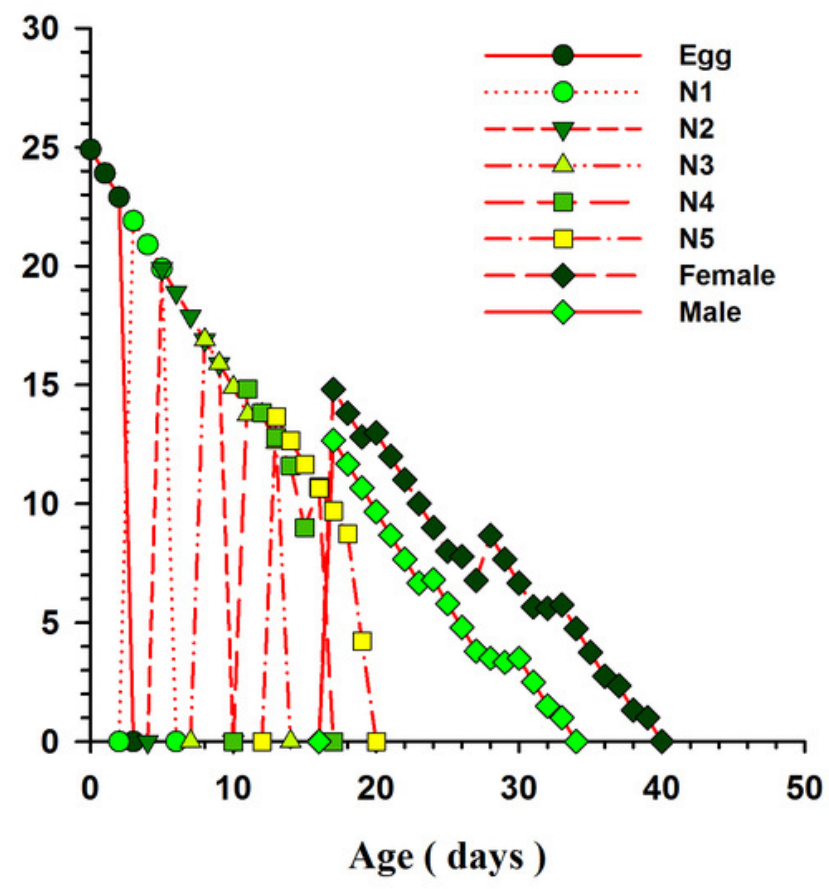


Figure 5

Age-stage specific reproductive values $\left(v_{x j}\right)$ of $O$. strigicollis praying on whitefly species

The reproductive curve $\left(v_{x j}\right)$ indicated that the presence of $B$. tabaci (A) had a more positive effect on O. strigicollis reproduction than T. vaporariorum (B).

A

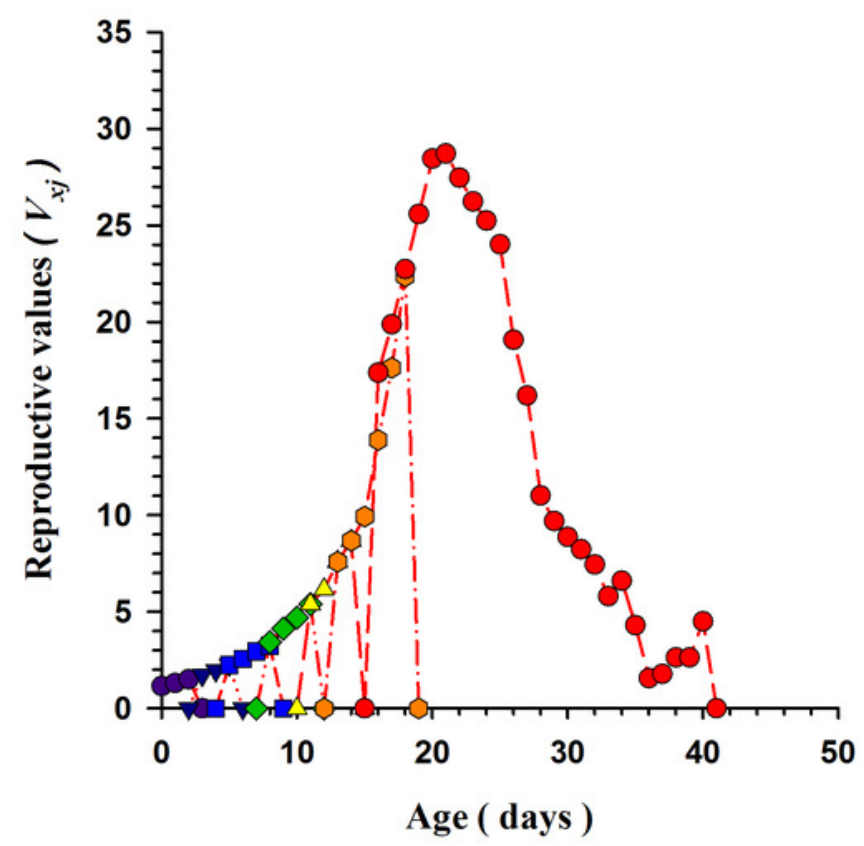

B

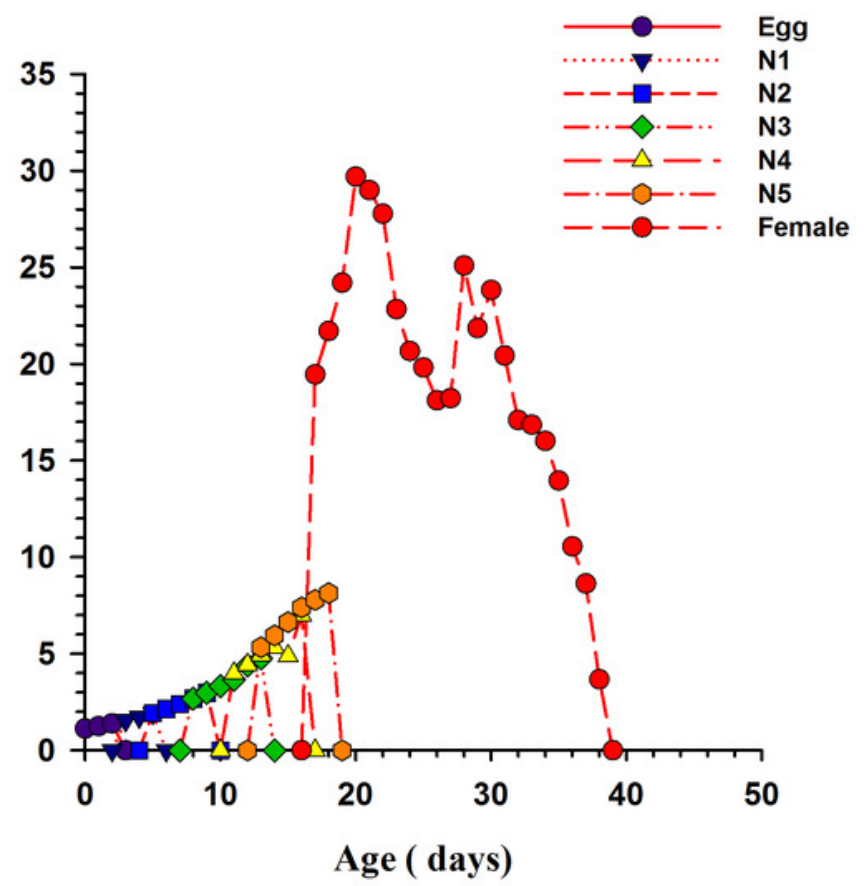

